\title{
The Use of Percutaneous Thermal Sensing Microchips for Body Temperature Measurements in Horses Prior to, during and after Treadmill Exercise
}

\author{
Hyungsuk Kang ${ }^{1}{ }^{\circledR}$, Rebeka R. Zsoldos ${ }^{1}$, , Solomon M. Woldeyohannes ${ }^{2}$, John B. Gaughan ${ }^{1}$ \\ and Albert Sole Guitart $2, *$ (D) \\ 1 School of Agriculture and Food Sciences, The University of Queensland, Gatton, QLD 4343, Australia; \\ hyungsuk.kang@uq.net.au (H.K.); r.zsoldos@uq.edu.au (R.R.Z.); j.gaughan@uq.edu.au (J.B.G.) \\ 2 School of Veterinary Science, The University of Queensland, Gatton, QLD 4343, Australia; \\ s.woldeyohannes@uq.edu.au \\ * Correspondence: a.guitart@uq.edu.au
}

Received: 10 November 2020; Accepted: 26 November 2020; Published: 2 December 2020

Simple Summary: During exercise, horses produce heat from working muscles, and this heat, under certain circumstances, may accumulate in the body. Conduction, convection, radiation, and evaporation are the primary heat transfer mechanisms for the control of body temperature. Horses that undergo strenuous exercise in hot and humid environments may have heat production that exceeds their ability to dissipate the heat. Therefore, the horse could be at risk from postexercise exertional heat illness, possibly leading to heat shock and death. To avoid this outcome, many Thoroughbred racehorses are cooled-down postracing by using water application (ice-cold water or ambient temperature water), fans, combinations of water application and fans, or water application followed by scraping the water off the horse. Early detection of the clinical signs of exertional heat illness and adequate treatments are important to prevent severe hyperthermia and irreversible thermal damage. The development and application of technology that will provide accurate, rapid, safe, and noninvasive monitoring of body temperature changes might help the detection of postrace exertional heat illness in equine athletes. Implanted percutaneous thermal sensing microchip (PTSM) is a reliable method to measure body temperature in horses; however, the optimal location within the body of the horse needs to be determined.

Abstract: Accurately measuring body temperature in horses will improve the management of horses suffering from or being at risk of developing postrace exertional heat illness. PTSM has the potential for measuring body temperature accurately, safely, rapidly, and noninvasively. This study was undertaken to investigate the relation between the core body temperature and PTSM temperatures prior to, during, and immediately after exercise. The microchips were implanted into the nuchal ligament, the right splenius, gluteal, and pectoral muscles, and these locations were then compared with the central venous temperature, which is considered to be the "gold standard" for assessing core body temperature. The changes in temperature of each implant in the horses were evaluated in each phase (prior to, during, and immediately postexercise) and combining all phases. There were strong positive correlations ranging from 0.82 to $0.94(p<0.001)$ of all the muscle sites with the central venous temperature when combining all the phases. Additionally, during the whole period, PTSM had narrow limits of agreement (LOA) with central venous temperature, which inferred that PTSM is essentially equivalent in measuring horse body temperature. Overall, the pectoral PTSM provided a valid estimation of the core body temperature. 
Keywords: horse; body temperature; percutaneous thermal sensing microchip; central venous temperature; treadmill exercise

\section{Introduction}

Thoroughbred horse racing is one of the most attractive events among horse competitions in Australia [1,2]. According to Racing Australia [1,2], 19,409 and 19,369 races were held in Australia during the 2017/18 and 2018/19 season, respectively, and 35,107 and 35,196 horses were raced during the respective seasons. During the two seasons, horses were raced on average over a $1000 \mathrm{~m}$ track, which they completed in $56 \mathrm{~s}$, equating to a speed of $17.86 \mathrm{~m} / \mathrm{s}$ [1]. The horses raced under various weather conditions, including heatwaves. Several states in Australia have policies in place to guide the Thoroughbred racing industry to protect the welfare of the horses racing and training in hot weather [3-7].

It was reported by Hodges et al. [8] that strenuous exercise, such as Thoroughbred racing, requires horses to expend a large amount of energy, which produces metabolic heat in muscles leading to an increase in body temperature of $1^{\circ} \mathrm{C}$ for every one minute of racing. Horses are normally able to control this accumulated body heat by dissipating heat to the environment via conduction, convection, radiation, and evaporation [8]. However, if the exercise is prolonged, especially during hot or hot and humid weather, horses may have limited capacity to dissipate the accumulated body heat [9]. Furthermore, unlike humans or other animal athletes, horses have a large body mass with a small body surface area, which further restricts the dissipation of body heat $[10,11]$.

As stated, when exercise is prolonged during hot or hot and humid weather, heat dissipation may be limited and, eventually, heat transfer may be reversed, i.e., the animal does not dissipate heat to the environment and may actually gain heat from the environment $[9,12,13]$. Even if the transfer by convection and radiation are reversed, the horse may still be able to dissipate body heat via sweating even when weather conditions are such that the rate of sweat evaporation is reduced [13]. However, horses have thick, waterproof hair, which interrupts the evaporative cooling of sweat by blocking its exposure to air [14]. The heat dissipation efficiency of the sweat running off the skin is only 5 to $10 \%$ of the sweat evaporation $[13,15]$, so evaporative heat loss is critical if horses are to maintain body temperature within a tolerable range. To support evaporation from the body surface during the hot or hot and humid condition, horses produce a surfactant protein, Latherin, and when mixed with sweat, it helps the wetting of the hair by sweat, improves evaporation, and decreases the amount of sweat running off the surface of the animal $[8,14,16]$. Under hot or hot and humid conditions, prolonged exercise may cause exertional heat illness (EHI), dehydration, collapse, and death [17,18]. When the central blood, the hypothalamic, and muscle temperatures reach $42.5{ }^{\circ} \mathrm{C}, 41.5{ }^{\circ} \mathrm{C}$, and $45^{\circ} \mathrm{C}$, respectively, horses may show signs of hyperthermia [15]. It has been demonstrated that blood temperature is a very sensitive measure of core body temperature in horses during exercise [9,19-22].

Monitoring weather conditions before and during a race event is essential for the safety of the animal. In terms of exertional heat illness or heat-related regulations, the wet-bulb globe temperature (WBGT) is used worldwide for monitoring sports events, such as the International Olympic Committee or Fédération Equestre Internationale competitions. Some racing organizations in Australia also use the WBGT index to aid in the decision-making process of weather safety prior to a race. When the forecast WBGT is above $26{ }^{\circ} \mathrm{C}$, it is recommended that organizers consider modifying or canceling the race. Governing bodies in Australia (Racing Queensland, Thoroughbred Racing South Australia, Racing New South Wales, and Racing Victoria) recommend taking extra care, such as providing an additional veterinarian at the track, ensuring the availability of adequate drinking water, and washing bays for horses at the events. In 2017, Equestrian Australia (EA) announced that when WBGT is above $28^{\circ} \mathrm{C}$, extra care and precautions are required to limit overheating of horses. However, there is an overall lack of guidelines for the recognition, prevention, and treatment of postrace EHI. As reported by Brownlow 
et al. [23], a horse with EHI shows increased rates of respiration and heart rate, slow capillary refill times, loss of consciousness, and some dangerous behaviors, such as kicking out randomly or lunging forward. To prevent brain damage, blood flow to the brain is restricted during hyperthermia, which can cause cerebral ischemia and brain edema. The induced brain damage results in central nervous system dysfunction leading to a loss of normal reflex responses, headache, collapse, or coma. Several methods can be used to reduce accumulated body heat after racing, such as taking the horses into an air-conditioned room, spraying cool water and fanning, pouring cool water on the skin, placing on ice collar of the neck, or using intravenous detomidine hydrochloride (a sedative) to reduce and to attenuate clinical signs of central nervous system (CNS) dysfunction [24-29]. However, it is not clear when more aggressive actions should be undertaken to save a horse from the effects of excessive heat load. Furthermore, there are currently no methods to detect early or mild postrace EHI cases. If body temperature could be measured accurately, safely, quickly, and noninvasively, then early detection and management of EHI would be possible.

Many methods are used to measure body temperature, such as gastrointestinal pills (gastrointestinal temperature), infrared thermal image (eye or skin temperature), central venous temperature, digital thermometer (rectal temperature), or using percutaneous thermal sensing microchips (PTSM) (muscle temperature) [22,30-33]. However, rectal thermometry is the most commonly used method to estimate core body temperature [34,35].

Rectal thermometry is an inexpensive technique, yet it is also time- and labor-consuming to perform, and may inflict local injury in horses, particularly during repeated samplings, and commonly induces handling stress or requires the use of sedatives. However, obtaining the rectal temperature of a horse immediately postexercise can also be dangerous and infeasible for the operator due to the restless behavior, especially in highly excitable horses and the constant movement of the animal while it is recovering from strenuous exercise. Furthermore, if the horse is exhibiting signs of postrace EHI, such as irritability and uncooperative behavior or kicking out, it will be unsafe and challenging to obtain the rectal temperature. Infrared temperature image has been used as a method to measure horse body temperature, but it may be affected by sunlight and therefore may be of limited practical value as an assessment of core body temperature [36].

In this study, it was hypothesized that PTSMs would accurately measure body temperature changes in horses. There are a lack of data on testing PTSMs usage in horses during exercise and immediately after exercise. In addition, no previous studies have tested PTSMs implanted in various locations of the horses' body [35,37]. The aim of the present study was to document the relationship between the central venous temperature (as the core body temperature) and PTSMs temperatures in various muscle sites during and immediately after exercise.

\section{Materials and Methods}

\subsection{Animals}

Eight unconditioned adult horses (7 geldings and 1 mare; 4 Thoroughbred and 4 Standardbred) ranging from 4 to 12 years old (average $7 \pm 3$ years old) and 455 to $545 \mathrm{~kg}$ body weight (average $493 \pm 31 \mathrm{~kg}$ ) were used in the study. The horses are part of the research herd at The University of Queensland (Gatton Campus), and they are routinely housed in groups of 10 to 15 horses in large grazing paddocks located on the Gatton campus. Ad libitum access to pasture and hay is provided with oat hay ( $1.5 \%$ of body weight) once or twice a week. The horses used in the study were not exercised during the 3 months prior to the commencement of the study. During the experiment, the animals were housed in small yards adjacent to the UQ VETS, Equine Specialist Hospital, The University of Queensland Gatton campus. Water was available ad libitum, and 1.5\% of body weight of lucerne hay was provided per day. The use of animals and all experimental procedures were approved by the Animal Ethics Committees (AEC) of The University of Queensland (Approval No. SAFS/431/18). All horses were shod prior to the commencement of the study. A general physical and lameness 
examination was performed at walk and trot by an equine surgeon specialist (A.S.G.) before the experiment to ensure that all of the horses used were healthy and sound. Full details of the exercise regimen are provided below.

\subsection{Microchipping}

Percutaneous thermal sensing microchips (LifeChip ${ }^{\circledR}$ with Bio-thermo ${ }^{\mathrm{TM}}$; Destron Fearing ${ }^{\mathrm{TM}}$; TX, USA), which contained a passive transponder programmed temperature sensor, were implanted two weeks before the commencement of the study. The horses were placed in a crush and sedated using xylazine (0.3-0.4 mg/kg body weight (BDW IV)). The implantation sites were clipped and surgically prepped using betadine and alcohol. Three milliliters of local anesthetic (Lignocaine Hydrochloride $20 \mathrm{mg} / \mathrm{mL}$ ) was injected subcutaneously five minutes before implantation of the microchips. The microchip was inserted perpendicular to the skin to the maximum depth allowed by the presterilized 12-gauge needle assembly containing the transponder.

The sites were determined using set parameters to ensure uniformity of their position. The percutaneous thermal sensing microchips were implanted into the nuchal ligament (only in the first two horses) halfway between the poll and the withers into the right splenius muscle halfway between the poll and the middle of the scapular spine, into the right gluteal muscle halfway between the tail head and the right tuber coxae, and into the right pectoral muscle in the middle of the right cranial pectoral muscle. The nuchal ligament PTSM was inserted dorsally following the same guidelines insertions as the conventional ID microchips.

The position of the microchips was followed up with ultrasound (MyLab Delta; Esaote S.p.A; Genova; Italy) examinations with a linear transducer (3-11 $\mathrm{MHz}$ frequency) to detect any abnormalities in the surrounding area after two months of implantation.

A preliminary study using two horses, fitted with a central venous temperature probe (see below) and PTSMs placed in the nuchal ligament and right gluteal muscle area, was undertaken. After observing a weak correlation and statistically nonsignificant data $(r=0.01, p=0.93)$ between the nuchal ligament temperatures and central venous temperatures, the study design was modified so that PTMS were placed in the right splenius muscle, the right pectoral muscle, and the right gluteal muscle of 8 horses (including the two used in the preliminary study). The present study includes the results of these 8 horses.

\subsection{Central Venous Temperature $\left(T_{C V}\right)$ Probe Insertion}

A small area in the cranial third of the jugular groove was clipped and aseptically prepared before the initiation of the treadmill exercise. A type T flexible implantable thermocouple (Physitemp Instrument; Clifton, NJ, USA) was introduced into the jugular vein through the lumen of a 14 Gauge 3.25 inches $\left(8 \mathrm{~cm}\right.$ ) intravenous catheter (Angiocath ${ }^{\mathrm{TM}}$; Becton-Dickinson and company; Franklin Lakes, NJ, USA). The thermocouple was introduced $80 \mathrm{~cm}$ from the IV catheter within the jugular vein toward the thorax. The temperature was displayed on a monitor (Thermalert model TH-8; Physitemp Instrument; Clifton, NJ, USA).

\subsection{Rectal Temperature $\left(T_{R}\right)$ Probe Placement}

A temperature data logger (HOBO Pro v2; U23-002; Onset Computer Corporation; Bourne, MA, USA) was used to obtain rectal temperature $\left(T_{R}\right)$ during exercise. A $184 \mathrm{~cm}$ long thermal sensor was fed through a universal insemination pipette for mares and introduced 40 to $50 \mathrm{~cm}$ into the rectum. Fecal content was removed prior to insertion of the thermal sensor. The data logger was secured to the tail using vet wrap. 


\subsection{Data Collection}

\subsubsection{Exercise Program}

All horses were familiarized and habituated to the treadmill (Veterinary Pit Model 980; Classic Treadmills Australia PTY LTD; QLD, Australia) and the microchip scanners two days before data collection. Because all horses were exposed to the treadmill in previous studies, only one session of habituation was required. This consisted of walking speed at $2 \mathrm{~m} / \mathrm{s}$ for approximately 2 min followed by trotting at $4 \mathrm{~m} / \mathrm{s}$ for $2.5 \mathrm{~min}$ and cantering at 6 to $7 \mathrm{~m} / \mathrm{s}$ for $1 \mathrm{~min}$. All horses moved comfortably on the treadmill and transition well between the different gaits. No signs of distress or incoordination were observed during habituation. Microchip scanners were used while the horses were exercised to habituate them to the operators' movement and scanner noise.

During the experiment, each horse underwent a standardized treadmill exercise program, where slight variation on the speed (max speed range between 8 and $10 \mathrm{~m} / \mathrm{s}$ ) and duration (between 8 and $11.5 \mathrm{~min}$ ) of the exercise was adapted to their individual fitness levels. The horses were warmed up by walking them for $5 \mathrm{~min}$ in an undercover area with a hard floor surface next to the treadmill room. Horses were walked in this area both pre- and postexercise. The exercise began at the speed of $2 \mathrm{~m} / \mathrm{s}$ for $30 \mathrm{~s}$, with the treadmill being set at a $5 \%$ incline. The speed was then increased to $4 \mathrm{~m} / \mathrm{s}$ and maintained for $2.5 \mathrm{~min}$. The speed was then increased from 6 to $8 \mathrm{~m} / \mathrm{s}$ to change the gait from trotting to cantering and then to galloping. Once the gait changed, the speed increased by $1 \mathrm{~m} / \mathrm{s}$ every minute until the $\mathrm{T}_{\mathrm{CV}}$ reached $41^{\circ} \mathrm{C}$. When the $\mathrm{T}_{\mathrm{CV}}$ reached $41{ }^{\circ} \mathrm{C}$, the treadmill speed was reduced to $4 \mathrm{~m} / \mathrm{s}$ and maintained at this speed for $2 \mathrm{~min}$. Two wall fans were operated in front of the treadmill machine with approximately a $1.5 \mathrm{~m}$ distance and $2.5 \mathrm{~m}$ from the floor on the wall at $5 \mathrm{~m} / \mathrm{s}$ just above the level of the treadmill during the exercise. Following the $10 \mathrm{~min}$ of hand-held walking, the horses were washed with cold tap water and returned to the small yards near the Equine Specialist Hospital.

\subsubsection{Temperature Acquisition}

The microchip temperature in the nuchal ligament $\left(\mathrm{T}_{\mathrm{NL}}\right)$, the right splenius muscle $\left(\mathrm{T}_{\mathrm{SM}}\right)$, the right gluteal muscle $\left(\mathrm{T}_{\mathrm{GM}}\right)$, and the right pectoral muscle $\left(\mathrm{T}_{\mathrm{PM}}\right)$ were measured using microchip scanners (GPR+; Destron Fearing ${ }^{\mathrm{TM}}$; Dallas, TX, USA). Two scanners were used so that the temperature of the different sites could be obtained at the same time. Microchip temperatures were acquired once before the commencement of treadmill exercise and then every $30 \mathrm{~s}$ during the treadmill exercise. The temperatures were then measured at one-minute intervals during the cool-down walk phase. Central venous temperature $\left(\mathrm{T}_{C V}\right)$ and rectal temperature $\left(\mathrm{T}_{R}\right)$ data were obtained at $1 \mathrm{~s}$ intervals. The $T_{C V}$ and $T_{R}$ data were extracted to match the time points of the microchip temperature measurements.

\subsubsection{Data Processing}

Temperature data $\left(\mathrm{T}_{\mathrm{CV}}, \mathrm{T}_{\mathrm{R}}, \mathrm{T}_{\mathrm{SM}}, \mathrm{T}_{\mathrm{GM}}, \mathrm{T}_{\mathrm{NL}}, \mathrm{T}_{\mathrm{PM}}\right)$ were pooled from the eight horses to document the changes in the body temperature during the experiment. The temperatures were grouped into the following phases: prior to exercise (Phase A; static phase), during exercise on the treadmill (Phase B; dynamic phase), immediately after exercise (Phase C; static phase), and cool-down walk (Phase D; dynamic phase) (Figure 1).

Eight temperature readings were recorded per horse for each temperature acquisition site during Phases A and C. A minimum of 15 temperature readings were recorded per horse for each temperature acquisition during Phase $B$, and a minimum of 8 temperature readings were recorded per horse for each temperature acquisition during Phase D (Figure 1). 


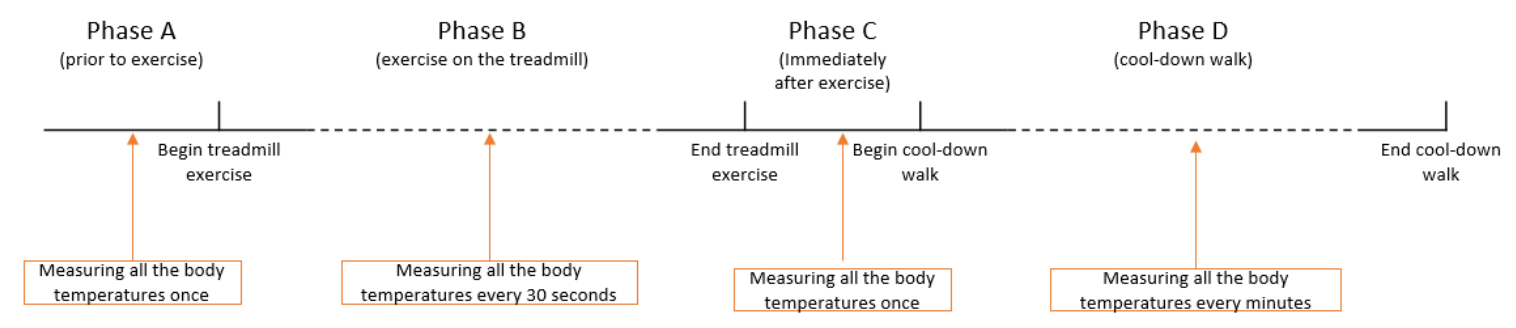

Figure 1. Exercise program by phases and body temperature acquisition points.

\subsection{Statistical Analysis}

All of the PTSM temperatures and $T_{R}$ were paired with $T_{C V}$ (e.g., $T_{C V} / T_{P M}$ pair, $T_{C V} / T_{G M}$ pair, $\mathrm{T}_{\mathrm{CV}} / \mathrm{T}_{\mathrm{SM}}$ pair, and $\mathrm{T}_{\mathrm{CV}} / \mathrm{T}_{\mathrm{R}}$ pair) to calculate the correlation and differences between $\mathrm{T}_{\mathrm{CV}}$, the core body temperature, and the other body temperatures prior to, during, and after treadmill exercise.

All statistical analyses were conducted in $\mathrm{R}$ [38]. The normal distribution of the data was investigated using a Shapiro-Wilk test. The significance level was set at $p<0.05$.

The correlation coefficients of the temperature readings were computed to determine the relationships between temperature pairs using Pearson and Spearman rank tests. In addition, the limit of agreement (LOA) was computed to assess the agreement in temperature readings obtained using $\mathrm{T}_{\mathrm{CV}}, \mathrm{T}_{\mathrm{GM}}, \mathrm{T}_{\mathrm{SM}}, \mathrm{T}_{\mathrm{PM}}$, and $\mathrm{T}_{\mathrm{R}}$. For each pair, a generalized linear regression model was fitted to get the mean bias and the standard error for computing the corresponding LOA.

For Phases $\mathrm{B}$ and $\mathrm{D}$ as dynamic phases, the repeated correlation coefficient for normally distributed data and the bootstrap method for non-normal data were used. The linear mixed-effects model was fitted to compute the LOA for the repeated temperature readings obtained using $\mathrm{T}_{\mathrm{CV}}$ and PTSM.

The correlation coefficients in the current study were determined based on previously used categories $(|r|=1$ : Perfect correlation, $0.9>|r|>0.7$ : Strong correlation, $0.6>|r|>0.4$ : Moderate correlation, $0.3>|r|>0.1$ : Weak correlation, and $r=0$ : Zero correlation) [39].

For theoretical explanation and model formula used in the analysis, refer to Appendix A.

\section{Results}

The average depth of the microchip from the skin surface to the right pectoral muscle was $2.01 \mathrm{~cm}$, to the right gluteal muscle it was $2.36 \mathrm{~cm}$, and to the right splenius muscle, it was $2.14 \mathrm{~cm}$ (Figure 2).

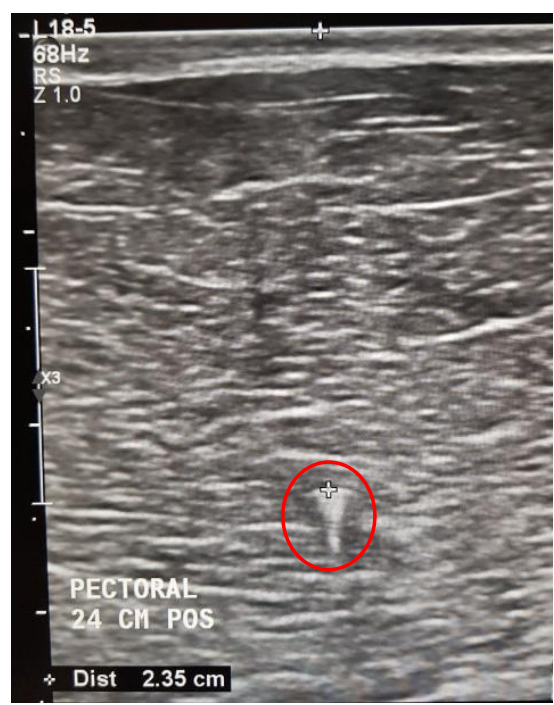

(a)

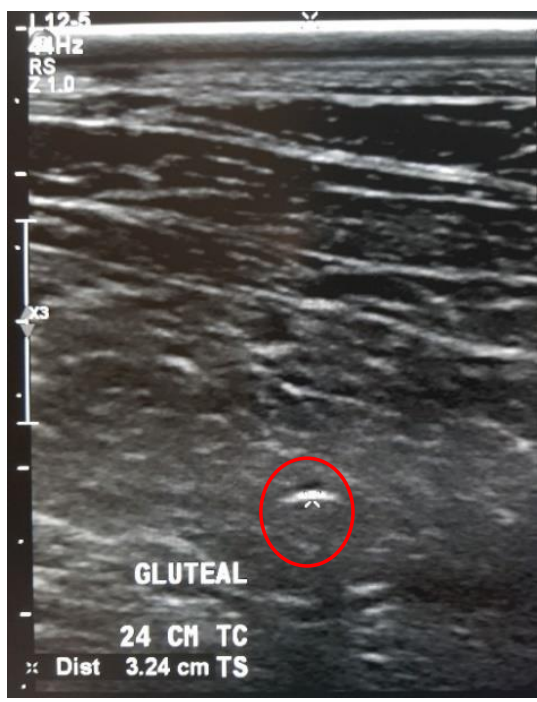

(b)

Figure 2. Ultrasound images of the right pectoral muscle (a) and right gluteal muscle (b) with a hyperechoic linear-structured microchip (red circle) within the muscle. 


\subsection{Results of the Preliminary Study $(n=2)$}

In the preliminary study $(n=2)$, the $\mathrm{T}_{\mathrm{CV}}$ had the highest correlation with $\mathrm{T}_{\mathrm{GM}}(r=0.84, p<0.001)$. There was no statistically significant relationship between $\mathrm{T}_{\mathrm{NL}}$ and $\mathrm{T}_{\mathrm{CV}}(r=0.01, p=0.93)$ or between $\mathrm{T}_{\mathrm{R}}$ and $\mathrm{T}_{\mathrm{CV}}(r=0.13, p=0.35)$. However, the correlation between $\mathrm{T}_{\mathrm{NL}}$ and $\mathrm{T}_{\mathrm{R}}$ was strong $(r=0.80$, $p<0.001)$.

\subsection{Results of the Final Study $(n=8)$}

\section{Body Temperatures and Its Paired Analysis}

Most of the recorded body temperatures were normally distributed. Non-normal distribution was found in $\mathrm{T}_{\mathrm{R}}(p=0.012)$ during Phase $\mathrm{A}$, in $\mathrm{T}_{\mathrm{SM}}(p=0.023)$ during Phase $\mathrm{C}$ and in $\mathrm{T}_{\mathrm{GM}}(p=0.008)$ during all phases (Phases A-D). Further details of these analyses are shown in Table A1 of Appendix A.

The changes in temperature at the different areas of the body are shown in Figure 3 . The central venous temperature peaked at the end of Phase B, whereas the PTSMs temperatures peaked during Phase $C\left(\mathrm{~T}_{\mathrm{PM}}\right.$ and $\left.\mathrm{T}_{\mathrm{GM}}\right)$ and the first minute of Phase $\mathrm{D}\left(\mathrm{T}_{\mathrm{SM}}\right)$. Rectal temperature increased until the end of the test, whereas the other body temperatures decreased during Phase D.

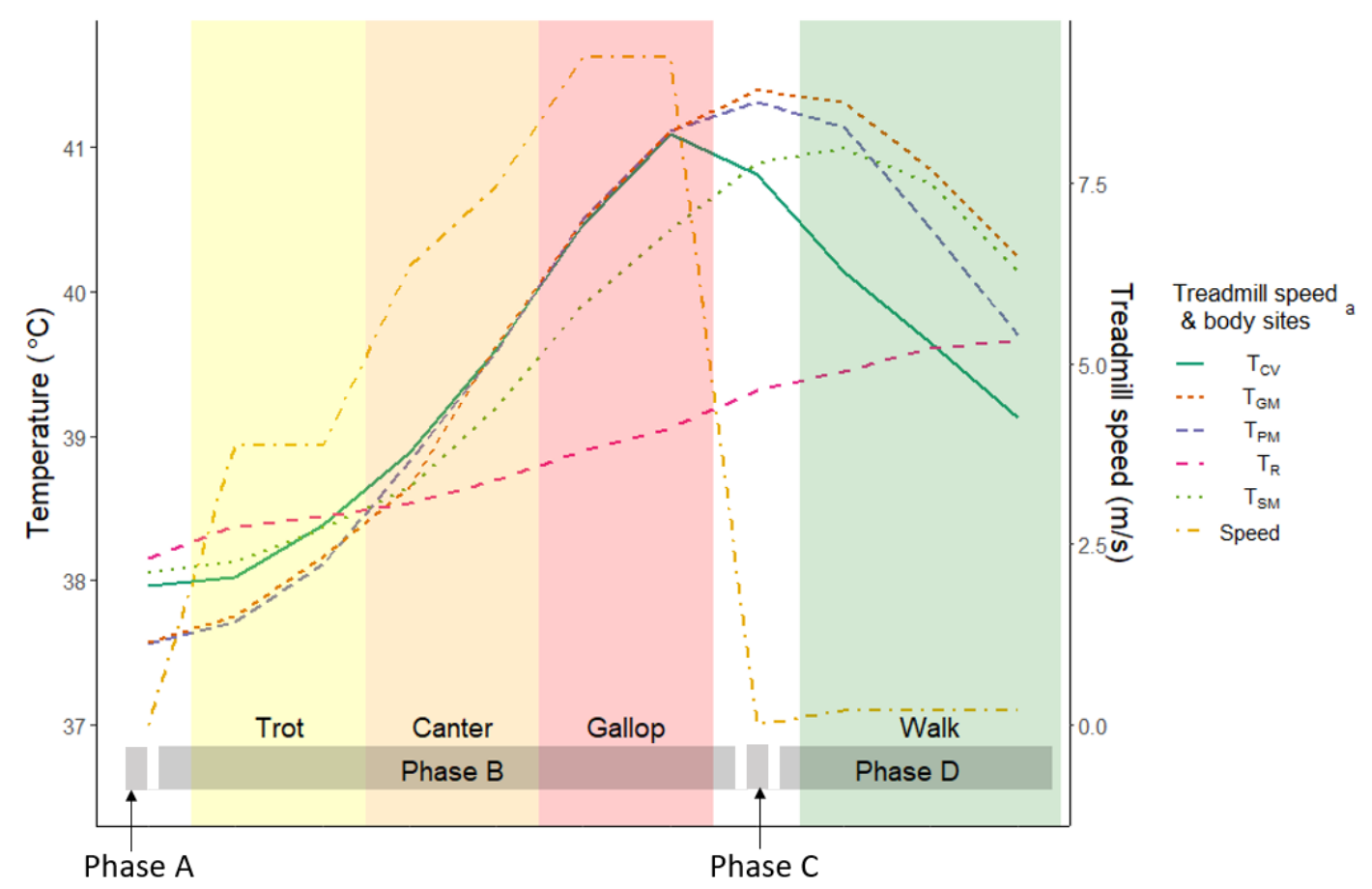

Figure 3. The average temperature during Phases A (prior to exercise), B (exercise on the treadmill), $\mathrm{C}$ (immediately after exercise), and $\mathrm{D}$ (cool-down walk) of the modified final study. ${ }^{\mathrm{a}} \mathrm{T}_{\mathrm{CV}}=$ central venous temperature, $\mathrm{T}_{\mathrm{PM}}=$ pectoral muscle temperature, $\mathrm{T}_{\mathrm{GM}}=$ gluteal muscle temperature, $\mathrm{T}_{\mathrm{SM}}=$ splenius muscle temperature, $\mathrm{T}_{\mathrm{R}}=$ rectal temperature.

Table 1 summarizes the horse body temperature readings from each method for the various phases of the experiment.

During Phase A, the lowest temperature was $36.90^{\circ} \mathrm{C}$ at $\mathrm{T}_{\mathrm{PM}}$ and the highest observed was $39.10^{\circ} \mathrm{C}$ at $\mathrm{T}_{\mathrm{SM}}$. Statistically significant and strong correlations were observed for $\mathrm{T}_{\mathrm{CV}} / \mathrm{T}_{\mathrm{PM}}(r=0.95$, $p<0.001)$ and for $\mathrm{T}_{\mathrm{CV}} / \mathrm{T}_{\mathrm{SM}}(r=0.87, p<0.001)$ pairs. There were no other statistical correlations.

During Phase B, both the lowest and highest temperatures were recorded at $\mathrm{T}_{\mathrm{SM}}\left(37.82{ }^{\circ} \mathrm{C}\right.$ and $40.37^{\circ} \mathrm{C}$, respectively). Statistically significant and strong correlations between temperature readings were observed for $\mathrm{T}_{\mathrm{CV}} / \mathrm{T}_{\mathrm{GM}}(r=0.84, p=0.01), \mathrm{T}_{\mathrm{CV}} / \mathrm{T}_{\mathrm{SM}}(r=0.83, p=0.01)$, and $\mathrm{T}_{\mathrm{CV}} / \mathrm{T}_{\mathrm{R}}(r=0.83$, $p=0.01)$ pairs, but no significant correlations were observed for the $\mathrm{T}_{\mathrm{CV}} / \mathrm{T}_{\mathrm{PM}}$ pair $(p=0.10)$. 
During Phase $\mathrm{C}$, the lowest temperature was $38.53{ }^{\circ} \mathrm{C}$ for $\mathrm{T}_{\mathrm{R}}$ and the highest was $42.00{ }^{\circ} \mathrm{C}$ at $\mathrm{T}_{\mathrm{SM}}$. There was no statistically significant correlation in the temperature pairs in this phase.

During Phase D, the lowest temperature was $38.91{ }^{\circ} \mathrm{C}$ for $\mathrm{T}_{\mathrm{PM}}$ and the highest was $41.61{ }^{\circ} \mathrm{C}$ at $\mathrm{T}_{\mathrm{SM}}$. There was no statistically significant correlation in the temperature pairs in this phase.

Combining all the data (Phases A-D), the lowest temperature was $36.90{ }^{\circ} \mathrm{C}$ for $\mathrm{T}_{\mathrm{PM}}$ and the highest was $42.00{ }^{\circ} \mathrm{C}$ for $\mathrm{T}_{\mathrm{SM}}$. Statistically significant and strong correlations were observed in all the temperature pairs. The highest correlation was observed in the $\mathrm{T}_{\mathrm{CV}} / \mathrm{T}_{\mathrm{PM}}$ pair $(r=0.94, p<0.001)$, and the second-highest correlation was in the $\mathrm{T}_{\mathrm{CV}} / \mathrm{T}_{\mathrm{GM}}$ pair $(r=0.90, p<0.001)$. The lowest correlation was between that of $\mathrm{T}_{\mathrm{CV}}$ and $\mathrm{T}_{\mathrm{R}}(r=0.71, p<0.001)$.

Table 1. Summary of body temperature readings of horses before, during, and after treadmill exercise.

\begin{tabular}{|c|c|c|c|c|c|c|c|c|c|}
\hline & \multicolumn{5}{|c|}{ Summary Stat } & \multicolumn{4}{|c|}{ Correlation (95\% CI) } \\
\hline & Mean & SD & Min & Max & $\mathrm{CC}$ & Correlation (r) & $p$-Value & LL & UL \\
\hline \multicolumn{10}{|c|}{ Phase A (Prior to exercise) } \\
\hline $\mathrm{T}_{\mathrm{CV}}$ & 37.96 & 0.41 & 37.40 & 38.60 & 1.09 & 1 & $<0.001$ & & \\
\hline $\mathrm{T}_{\mathrm{PM}}$ & 37.56 & 0.55 & 36.90 & 38.30 & 1.47 & 0.95 & $<0.001$ & 0.76 & 0.99 \\
\hline $\mathrm{T}_{\mathrm{GM}}$ & 37.58 & 0.41 & 37.00 & 38.30 & 1.08 & 0.59 & 0.12 & -0.20 & 0.91 \\
\hline $\mathrm{T}_{\mathrm{SM}}$ & 38.05 & 0.54 & 37.40 & 39.10 & 1.43 & 0.87 & $<0.001$ & 0.44 & 0.98 \\
\hline $\mathrm{T}_{\mathrm{R}}$ & 38.09 & 0.19 & 37.89 & 38.87 & 0.49 & 0.31 & 0.45 & -0.50 & 0.83 \\
\hline \multicolumn{10}{|c|}{ Phase B (Exercise on the treadmill) } \\
\hline $\mathrm{T}_{\mathrm{CV}}$ & 39.31 & 0.32 & 38.91 & 39.75 & 0.82 & 1 & $<0.001$ & & \\
\hline $\mathrm{T}_{\mathrm{PM}}$ & 39.17 & 0.43 & 38.68 & 39.58 & 1.10 & 0.81 & 0.10 & -0.25 & 0.99 \\
\hline $\mathrm{T}_{\mathrm{GM}}$ & 39.23 & 0.33 & 38.72 & 39.78 & 0.84 & 0.84 & 0.01 & 0.33 & 0.97 \\
\hline $\mathrm{T}_{\mathrm{SM}}$ & 39.05 & 0.73 & 37.82 & 40.37 & 1.87 & 0.83 & 0.01 & 0.31 & 0.97 \\
\hline $\mathrm{T}_{\mathrm{R}}$ & 38.66 & 0.42 & 38.06 & 39.46 & 1.10 & 0.83 & 0.01 & 0.30 & 0.97 \\
\hline \multicolumn{10}{|c|}{ Phase C (Immediately after exercise) } \\
\hline $\mathrm{T}_{\mathrm{CV}}$ & 40.81 & 0.14 & 40.60 & 41.00 & 0.33 & 1 & $<0.001$ & & \\
\hline $\mathrm{T}_{\mathrm{PM}}$ & 41.31 & 0.48 & 40.50 & 41.90 & 1.15 & -0.09 & 0.83 & -0.75 & 0.66 \\
\hline $\mathrm{T}_{\mathrm{GM}}$ & 41.39 & 0.22 & 41.10 & 41.80 & 0.54 & -0.42 & 0.30 & -0.87 & 0.41 \\
\hline $\mathrm{T}_{\mathrm{SM}}$ & 41.00 & 0.28 & 38.80 & 42.00 & 0.67 & 0.62 & 0.10 & -0.16 & 0.92 \\
\hline $\mathrm{T}_{\mathrm{R}}$ & 39.32 & 0.53 & 38.53 & 40.20 & 1.34 & 0.13 & 0.76 & -0.63 & 0.76 \\
\hline \multicolumn{10}{|c|}{ Phase D (Cool-down walk) } \\
\hline $\mathrm{T}_{\mathrm{CV}}$ & 39.59 & 0.20 & 39.31 & 40.00 & 0.50 & 1 & $<0.001$ & & \\
\hline $\mathrm{T}_{\mathrm{PM}}$ & 40.36 & 0.74 & 38.91 & 41.29 & 1.84 & 0.5 & 0.20 & -0.31 & 0.89 \\
\hline $\mathrm{T}_{\mathrm{GM}}$ & 40.77 & 0.38 & 40.11 & 41.25 & 0.92 & -0.43 & 0.29 & -0.87 & 0.39 \\
\hline $\mathrm{T}_{\mathrm{SM}}$ & 40.61 & 0.70 & 39.40 & 41.61 & 1.72 & -0.11 & 0.79 & -0.76 & 0.64 \\
\hline $\mathrm{T}_{\mathrm{R}}$ & 39.56 & 0.35 & 39.12 & 39.99 & 0.88 & 0.21 & 0.62 & -0.58 & 0.8 \\
\hline \multicolumn{10}{|c|}{ All the data (Phases A-D) } \\
\hline $\mathrm{T}_{\mathrm{CV}}$ & 39.42 & 1.07 & 37.40 & 41.00 & 2.70 & 1 & $<0.001$ & & \\
\hline $\mathrm{T}_{\mathrm{PM}}$ & 39.65 & 1.59 & 36.90 & 41.90 & 4.00 & 0.94 & $<0.001$ & 0.87 & 0.97 \\
\hline $\mathrm{T}_{\mathrm{GM}}$ & 39.95 & 2.53 & 37.00 & 41.80 & 6.34 & 0.90 & $<0.001$ & 0.80 & 0.95 \\
\hline $\mathrm{T}_{\mathrm{SM}}$ & 39.65 & 1.37 & 37.40 & 42.00 & 3.46 & 0.82 & $<0.001$ & 0.67 & 0.91 \\
\hline $\mathrm{T}_{\mathrm{R}}$ & 38.92 & 0.68 & 37.89 & 40.20 & 1.75 & 0.71 & $<0.001$ & 0.47 & 0.85 \\
\hline
\end{tabular}

$\mathrm{SD}=$ standard deviation, $\mathrm{CC}=$ correlation coefficient, $\mathrm{CI}=$ confidence interval, $\mathrm{LL}=$ lower limit, $\mathrm{UL}=\mathrm{upper}$ limit, $\mathrm{T}_{\mathrm{CV}}=$ central venous temperature, $\mathrm{T}_{\mathrm{PM}}=$ pectoral muscle temperature, $\mathrm{T}_{\mathrm{GM}}=$ gluteal muscle temperature, $\mathrm{T}_{\mathrm{SM}}=$ splenius muscle temperature, $\mathrm{T}_{\mathrm{R}}=$ rectal temperature.

\subsection{Results of Limit of Agreement ( $L O A$ )}

The average discrepancy between the methods (the bias indicated by a horizontal red line in the plots) was small (Figures 4-7). The limits of agreement (LOA) were narrow, and it can be inferred that the methods are essentially equivalent in measuring horse body temperature at various phases of the experiment (Figures 4-7). 
Phase A (Prior to exercise)
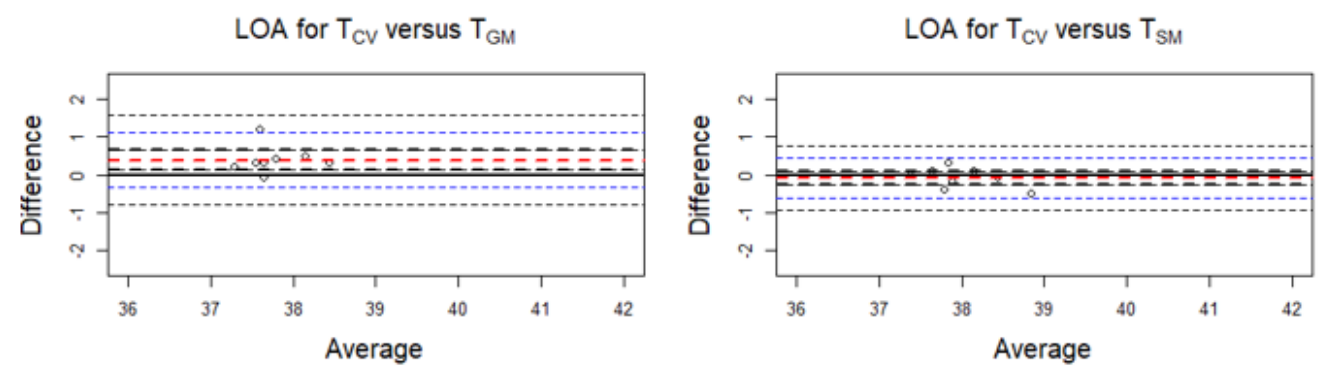

LOA for $T_{C V}$ versus $T_{P M}$
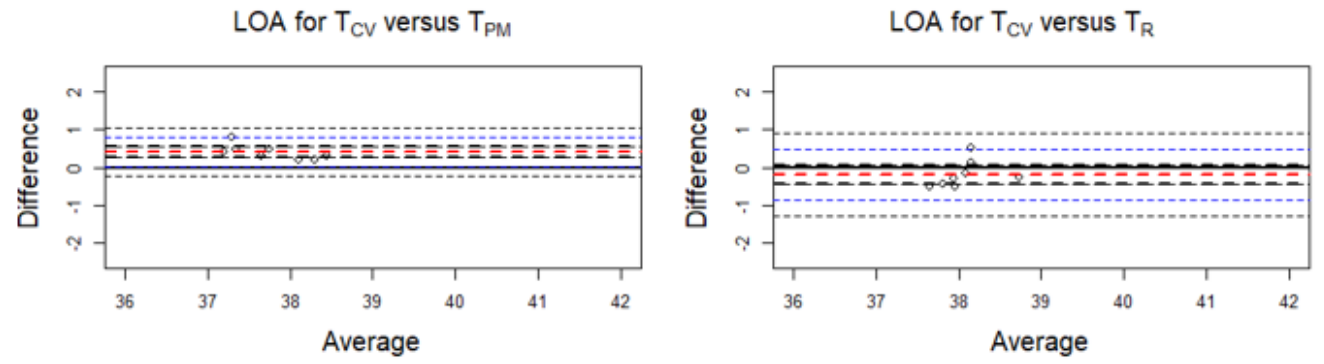

Figure 4. Limits of agreement (LOA) plots for the temperature pairs $\left(\mathrm{T}_{\mathrm{CV}} / \mathrm{T}_{\mathrm{GM}}, \mathrm{T}_{\mathrm{CV}} / \mathrm{T}_{\mathrm{SM}}, \mathrm{T}_{\mathrm{CV}} / \mathrm{T}_{\mathrm{PM}}\right.$, and $\mathrm{T}_{\mathrm{CV}} / \mathrm{T}_{\mathrm{R}}$ ) during Phase $\mathrm{A}$ (prior to exercise). The red horizontal dashed line indicates the mean bias. The blue horizontal dashed lines indicate the upper and lower limits. The black horizontal dashed lines indicate the $95 \%$ confidence intervals of the LOA. $\mathrm{T}_{\mathrm{CV}}=$ central venous temperature, $\mathrm{T}_{\mathrm{PM}}=$ pectoral muscle temperature, $\mathrm{T}_{\mathrm{GM}}=$ gluteal muscle temperature, $\mathrm{T}_{\mathrm{SM}}=$ splenius muscle temperature, $\mathrm{T}_{\mathrm{R}}=$ rectal temperature.

Phase B (Exercise on the treadmill)
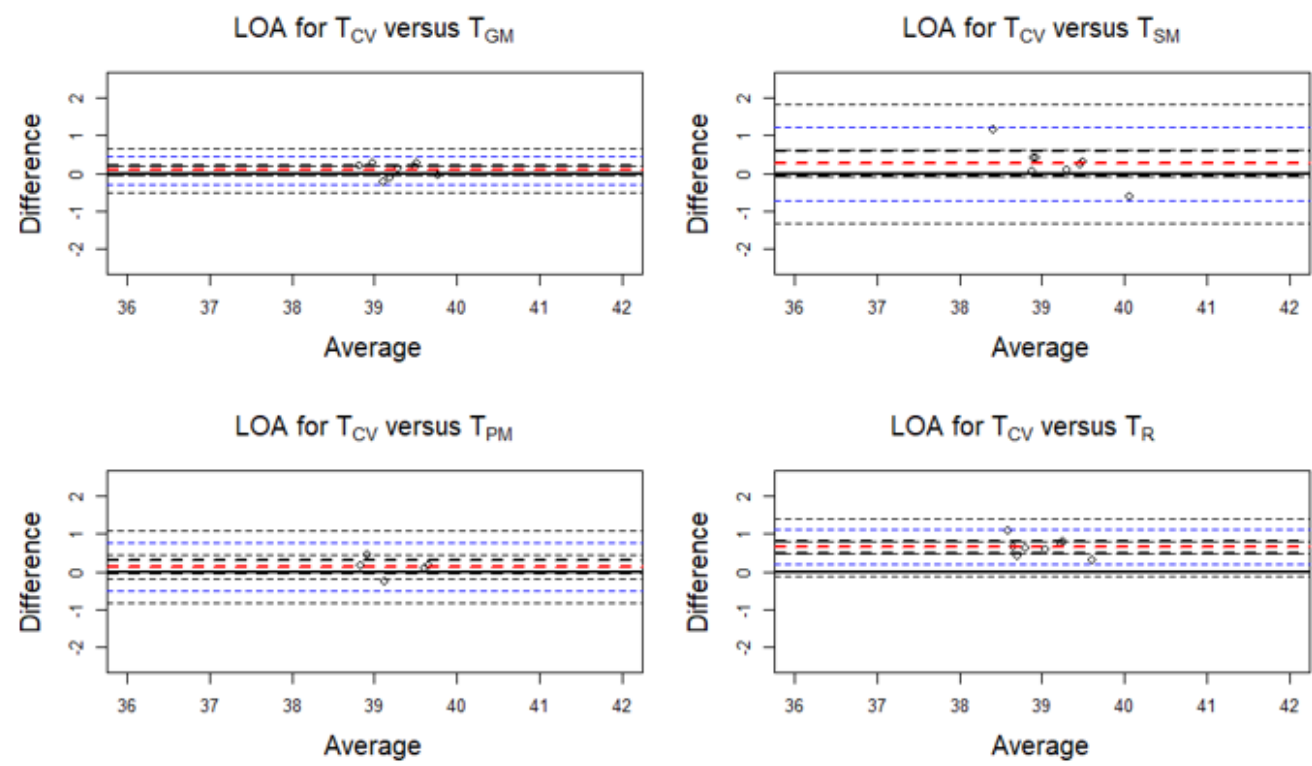

Figure 5. Limits of agreement (LOA) plots for the temperature pairs $\left(\mathrm{T}_{\mathrm{CV}} / \mathrm{T}_{\mathrm{GM}}, \mathrm{T}_{\mathrm{CV}} / \mathrm{T}_{\mathrm{SM}}, \mathrm{T}_{\mathrm{CV}} / \mathrm{T}_{\mathrm{PM}}\right.$, and $T_{C V} / T_{R}$ ) during Phase $B$ (exercise on the treadmill). The red horizontal dashed line indicates the mean bias. The blue horizontal dashed lines indicate the upper and lower limits. The black horizontal dashed lines indicate the $95 \%$ confidence intervals of the LOA. $\mathrm{T}_{\mathrm{CV}}=$ central venous temperature, $\mathrm{T}_{\mathrm{PM}}=$ pectoral muscle temperature, $\mathrm{T}_{\mathrm{GM}}=$ gluteal muscle temperature, $\mathrm{T}_{\mathrm{SM}}=$ splenius muscle temperature, $\mathrm{T}_{\mathrm{R}}=$ rectal temperature. 
Phase C (Immediately after treadmill)
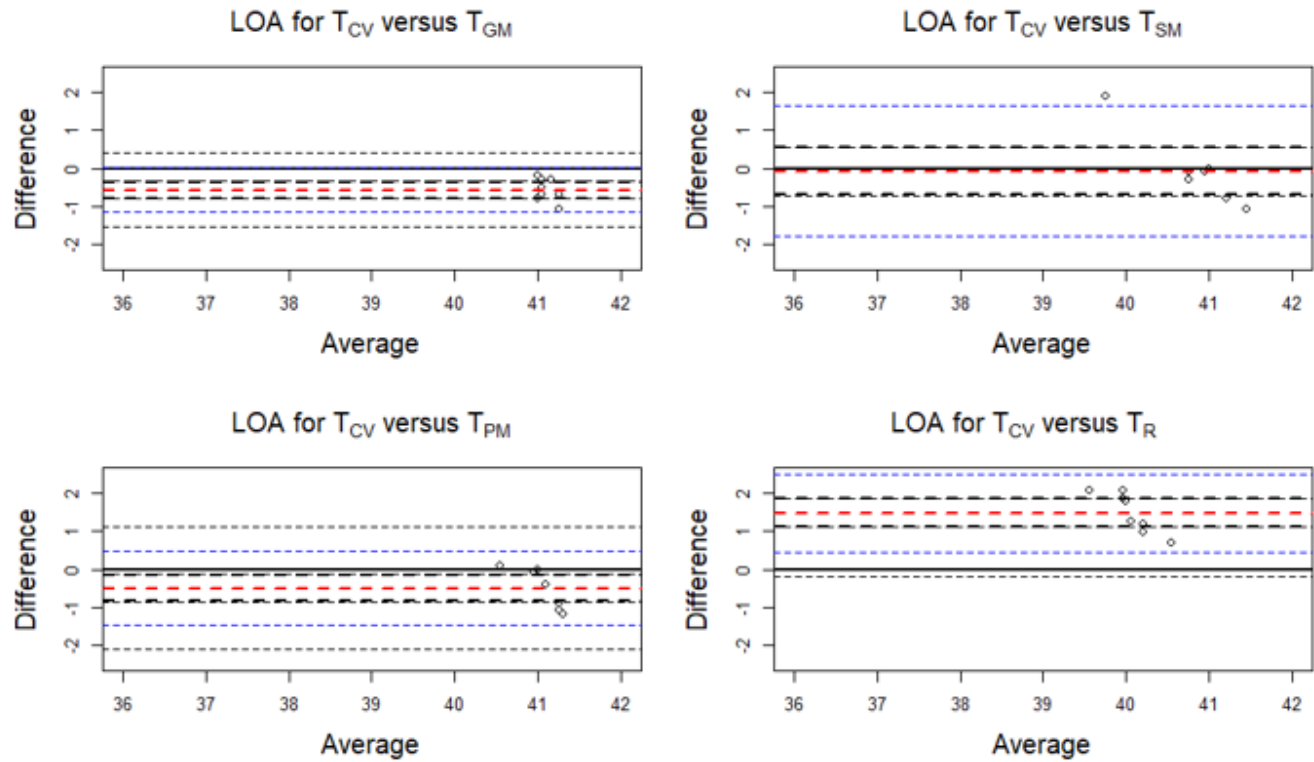

Figure 6. Limits of agreement (LOA) plots for the temperature pairs $\left(\mathrm{T}_{\mathrm{CV}} / \mathrm{T}_{\mathrm{GM}}, \mathrm{T}_{\mathrm{CV}} / \mathrm{T}_{\mathrm{SM}}, \mathrm{T}_{\mathrm{CV}} / \mathrm{T}_{\mathrm{PM}}\right.$, and $\mathrm{T}_{\mathrm{CV}} / \mathrm{T}_{\mathrm{R}}$ ) during Phase $\mathrm{C}$ (immediately after treadmill). The red horizontal dashed line indicates the mean bias. The blue horizontal dashed lines indicate the upper and lower limits. The black horizontal dashed lines indicate the $95 \%$ confidence intervals of the LOA. $\mathrm{T}_{\mathrm{CV}}=$ central venous temperature, $\mathrm{T}_{\mathrm{PM}}=$ pectoral muscle temperature, $\mathrm{T}_{\mathrm{GM}}=$ gluteal muscle temperature, $\mathrm{T}_{\mathrm{SM}}=$ splenius muscle temperature, $\mathrm{T}_{\mathrm{R}}=$ rectal temperature.

Phase D (Cool-down walk)
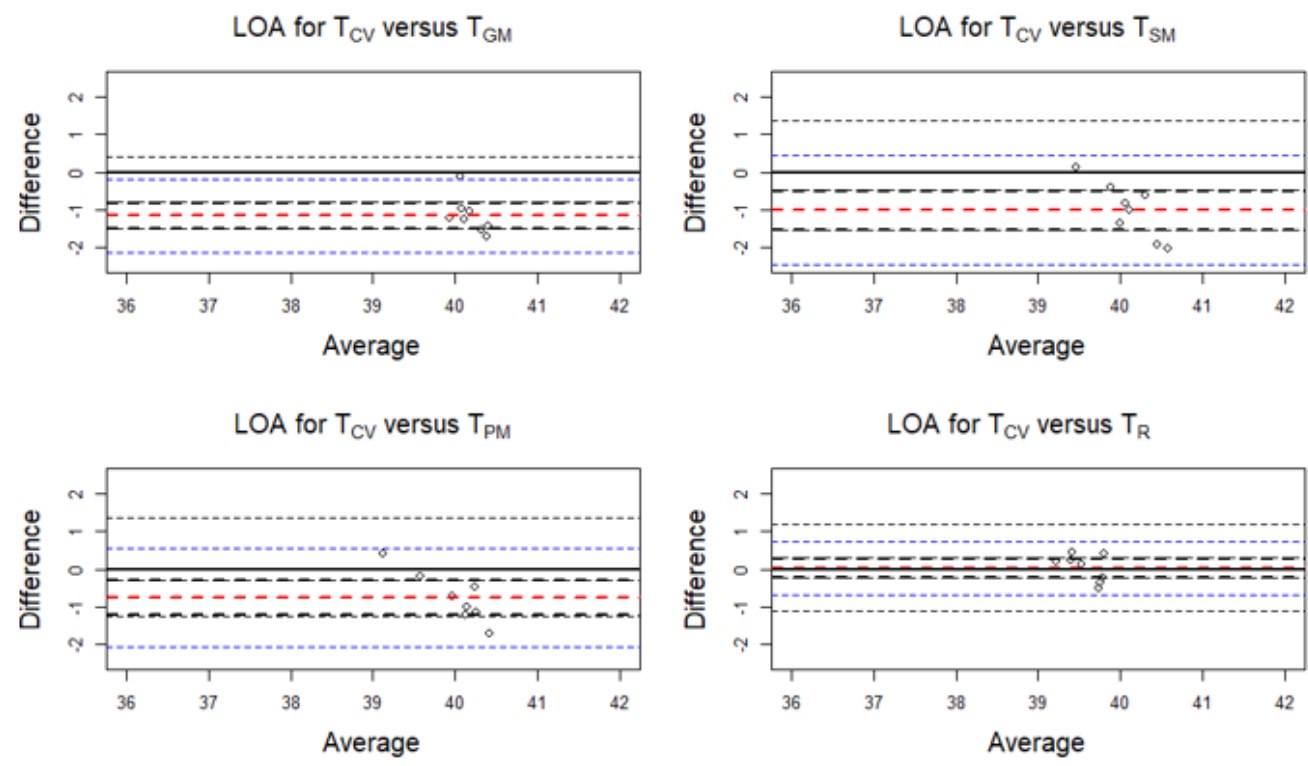

Figure 7. Limits of agreement (LOA) plots for the temperature pairs $\left(\mathrm{T}_{\mathrm{CV}} / \mathrm{T}_{\mathrm{GM}}, \mathrm{T}_{\mathrm{CV}} / \mathrm{T}_{\mathrm{SM}}, \mathrm{T}_{\mathrm{CV}} / \mathrm{T}_{\mathrm{PM}}\right.$ and $\mathrm{T}_{\mathrm{CV}} / \mathrm{T}_{\mathrm{R}}$ ) during Phase $\mathrm{D}$ (cool-down walk). The red horizontal dashed line indicates the mean bias. The blue horizontal dashed lines indicate the upper and the lower limit. The black horizontal dashed lines indicate the $95 \%$ confidence intervals of the $\mathrm{LOA} . \mathrm{T}_{\mathrm{CV}}=$ central venous temperature, $\mathrm{T}_{\mathrm{PM}}=$ pectoral muscle temperature, $\mathrm{T}_{\mathrm{GM}}=$ gluteal muscle temperature, $\mathrm{T}_{\mathrm{SM}}=$ splenius muscle temperature, $\mathrm{T}_{\mathrm{R}}=$ rectal temperature. 
During Phase A, higher temperatures were recorded for $\mathrm{T}_{\mathrm{SM}}(\mathrm{bias}=-0.088)$ and $\mathrm{T}_{\mathrm{R}}(\mathrm{bias}=-0.195)$ than $\mathrm{T}_{\mathrm{CV}}$. Lower temperatures were obtained from $\mathrm{T}_{\mathrm{GM}}($ bias $=0.388)$ and $\mathrm{T}_{\mathrm{PM}}(\mathrm{bias}=0.400)$ compared with $\mathrm{T}_{\mathrm{CV}}$.

During Phase $B$, temperatures obtained using $\mathrm{T}_{\mathrm{CV}}$ were higher than all the other methods.

During Phases $C$ and $D$, higher temperatures were recorded at $\mathrm{T}_{\mathrm{GM}}, \mathrm{T}_{\mathrm{SM}}$, and $\mathrm{T}_{\mathrm{PM}}$ compared with $\mathrm{T}_{\mathrm{CV}}$.

Similarly, Table A2 (in Appendix A) presents separate LOAs for the temperature readings taken during the various phases of the experiment.

\subsection{Results of Repeated Measured Correlation $\left(r_{m c}\right)$ during Phases B and D}

The repeated-measures correlation coefficients $\left(\mathrm{r}_{\mathrm{mc}}\right)$ for body temperatures acquired during Phases $\mathrm{B}$ and $\mathrm{D}$ indicated that there were significant correlations for all temperature pairs. The resulting $\mathrm{r}_{\mathrm{mc}}$ along with $95 \%$ bootstrap confidence intervals and $p$-values are summarized in Table 2. A strong positive correlation was calculated in the pair of $\mathrm{T}_{\mathrm{CV}} / \mathrm{T}_{\mathrm{PM}}\left(\mathrm{r}_{\mathrm{mc}}=0.93, p<0.001\right)$, followed by the $\mathrm{T}_{\mathrm{CV}} / \mathrm{T}_{\mathrm{GM}}$ pair $\left(\mathrm{r}_{\mathrm{mc}}=0.88, p<0.001\right)$ and the $\mathrm{T}_{\mathrm{CV}} / \mathrm{T}_{\mathrm{SM}}$ pair $\left(\mathrm{r}_{\mathrm{mc}}=0.73, p<0.001\right)$. Finally, a moderate positive correlation was observed in the pair of $\mathrm{T}_{\mathrm{CV}} / \mathrm{T}_{\mathrm{R}}\left(\mathrm{r}_{\mathrm{mc}}=0.51, p<0.001\right)$ (Table 2).

Table 2. Repeated-measures correlation coefficient $\left(r_{m c}\right)$ for body temperature readings in horses during Phases B (exercise on the treadmill) and D (cool-down walk).

\begin{tabular}{|c|c|c|c|c|}
\hline \multicolumn{2}{|c|}{$\mathbf{r}_{\mathrm{mc}}$} & $p$-Value & Lower Limit & Upper Limit \\
\hline $\mathrm{T}_{\mathrm{PM}}$ & 0.93 & $<0.001$ & 0.88 & 0.93 \\
\hline $\mathrm{T}_{\mathrm{GM}}$ & 0.88 & $<0.001$ & 0.84 & 0.91 \\
\hline $\mathrm{T}_{\mathrm{SM}}$ & 0.73 & $<0.001$ & 0.62 & 0.79 \\
\hline $\mathrm{T}_{\mathrm{R}}$ & 0.51 & $<0.001$ & 0.43 & 0.62 \\
\hline
\end{tabular}

$\mathrm{T}_{\mathrm{CV}}=$ central venous temperature, $\mathrm{T}_{\mathrm{PM}}=$ pectoral muscle temperature, $\mathrm{T}_{\mathrm{GM}}=$ gluteal muscle temperature, $\mathrm{T}_{\mathrm{SM}}=$ splenius muscle temperature, $T_{R}=$ rectal temperature.

During Phases $B$ and $D$, the muscle temperatures were higher than $\mathrm{T}_{\mathrm{CV}}\left(\mathrm{T}_{\mathrm{CV}} / \mathrm{T}_{\mathrm{GM}}\right.$, bias $=-0.459$; $\mathrm{T}_{\mathrm{CV}} / \mathrm{T}_{\mathrm{SM}}$, bias $=-0.260$; and $\mathrm{T}_{\mathrm{CV}} / \mathrm{T}_{\mathrm{PM}}$, bias $\left.=-0.319\right)$, whereas the $\mathrm{T}_{\mathrm{R}}$ was lower than $\mathrm{T}_{\mathrm{CV}}($ bias $=0.483)$. The average discrepancy between the temperatures (the bias indicated by a horizontal red line in the plots) was small (Figure 8). The limits of agreement (LOA) were narrow. Hence, with a narrow LOA and small bias, it can be inferred that the temperatures were essentially equivalent in measuring horse body temperature at various phases of the experiment. The scatter around the bias line gets larger as the average temperature readings get higher. Therefore, the consistency was decreased across the graph as the average increases (Figure 8).

Similarly, Table A3 (in Appendix A) presents separate LOAs for the temperature readings taken during Phases B and D. 


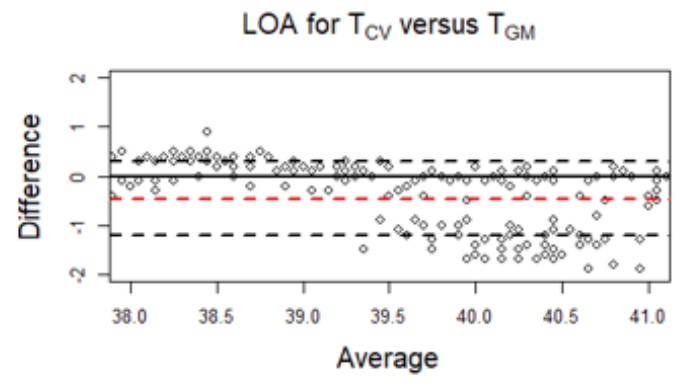

LOA for $T_{C V}$ versus $T_{P M}$

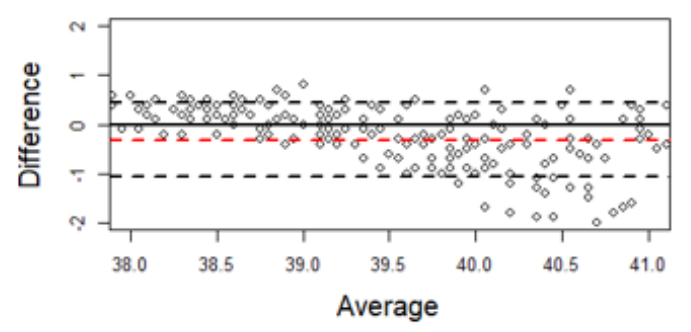

LOA for $T_{C V}$ versus $T_{S M}$

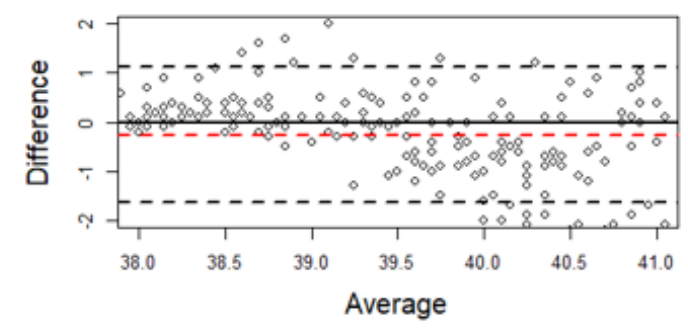

LOA for $T_{C V}$ versus $T_{R}$

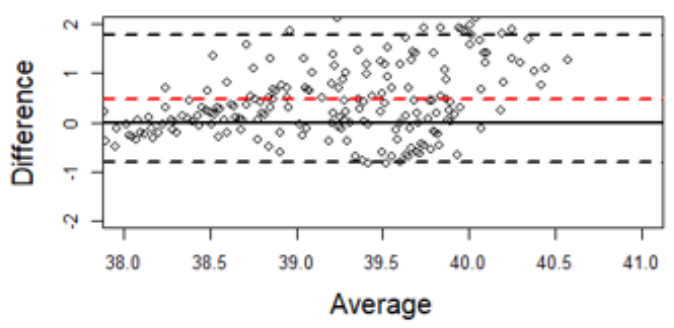

Figure 8. Limits of agreement (LOA) plots for the temperature pairs $\left(\mathrm{T}_{\mathrm{CV}} / \mathrm{T}_{\mathrm{GM}}, \mathrm{T}_{\mathrm{CV}} / \mathrm{T}_{\mathrm{SM}}, \mathrm{T}_{\mathrm{CV}} / \mathrm{T}_{\mathrm{PM}}\right.$, and $\mathrm{T}_{\mathrm{CV}} / \mathrm{T}_{\mathrm{R}}$ ) during Phases $\mathrm{B}$ (exercise on the treadmill) and $\mathrm{D}$ (cool-down walk). The red horizontal dashed line indicates the mean bias. The black horizontal dashed lines indicate the upper and the lower limit. $\mathrm{T}_{\mathrm{CV}}=$ central venous temperature, $\mathrm{T}_{\mathrm{PM}}=$ pectoral muscle temperature, $\mathrm{T}_{\mathrm{GM}}=$ gluteal muscle temperature, $\mathrm{T}_{\mathrm{SM}}=$ splenius muscle temperature, $\mathrm{T}_{\mathrm{R}}=$ rectal temperature.

\section{Discussion}

Percutaneous thermal sensing microchips have been previously used in a few horse studies [35,37]; however, this is the first study reporting the use of PTSMs in horses during and postexercise. The results from our data revealed that the optimal location for implantation of a PTSM is the pectoral muscle based on the strong correlation in the $\mathrm{T}_{\mathrm{CV}} / \mathrm{T}_{\mathrm{PM}}$ pair followed by the $\mathrm{T}_{\mathrm{CV}} / \mathrm{T}_{\mathrm{GM}}$ and $\mathrm{T}_{\mathrm{CV}} / \mathrm{T}_{\mathrm{SM}}$ pairs during strenuous exercise on the treadmill and cool-down walk immediately after the exercise.

The protocol of the preliminary study was modified due to the weak correlation between $\mathrm{T}_{\mathrm{NL}}$ and $\mathrm{T}_{\mathrm{CV}}$ during and immediately after exercise in the first two horses assessed. This finding is most likely related to the poor vascular supply of the nuchal ligament compared to other muscles, and this could explain the delayed temperature changes observed in $\mathrm{T}_{\mathrm{NL}}$ compared to $\mathrm{T}_{\mathrm{CV}}[40,41]$. The study of Robinson et al. [35] revealed that the PTSM in the nuchal ligament was sensitive to the surrounding environmental factors, such as ambient temperature, so the study recommended another body site to implant the microchip for reading body temperature.

Differences between the body temperatures observed at the end of Phases B and D (Figure 3) were due to the normal physiologic reaction of thermoregulation [18]. During exercise, an increase in metabolic heat production augments the rate at which heat in muscles can be dissipated to the environment in order to prevent dangerous elevations in tissue temperature. Upon the cessation of exercise, the rate of heat production may greatly exceed the rate of heat dissipation, leading to a sustained elevation of muscle temperature. During short-term, high-intensity exercise, the rate of heat production will exceed the rate of heat loss throughout the exercise, and the body temperature will continue to increase until the cessation of exercise. In a study by Marlin et al. [42], similar results were reported during $21 \mathrm{~min}$ of exercise on the treadmill (up to $10 \mathrm{~m} / \mathrm{s}$ of speed). The muscle, pulmonary artery, and rectal temperatures increased to $5.0^{\circ} \mathrm{C}, 4.8^{\circ} \mathrm{C}$, and $1.7^{\circ} \mathrm{C}$, respectively. In the present study, similar outcomes were observed during $10 \mathrm{~min}$ of exercise (up to $10 \mathrm{~m} / \mathrm{s}$ of speed). The PTSM temperatures in the muscles increased the most $\left(3.2^{\circ} \mathrm{C}\right)$, followed by central venous temperature $\left(2.8^{\circ} \mathrm{C}\right)$ and rectal temperature $\left(0.98^{\circ} \mathrm{C}\right)$. In this instance, a large proportion of the metabolic heat load will be dissipated during the postexercise period. The postexercise temperature response (rate of 
temperature decay) is influenced by convective heat transfer between blood and muscle and conductive heat transfer within the muscle. In the current study, PTSM temperatures followed the same pattern of a continuous increase of temperature until a few minutes after cessation of exercise and then a gradual decrease during the cooling phase. However, the muscle temperature differed depending on the location of the microchips. These differences could be due in part to factors such as differences in the muscle mass and energy turnover efficiency of the muscles used in the exercise activity and work intensity of those muscles [43-45].

The depth and location of the PTSM within the same muscle group may be different between horses. Different temperature gradients within the muscle both at rest and during exercise have been reported in humans [46-48]. Most commonly, the highest temperature is found in the deepest part of the muscle. Different parts of the same muscle may have different activity levels during exercise as well as different blood flows [46]. In humans and laboratory animals, it has been demonstrated that aging causes a profound redistribution of skeletal muscle blood flow within and between muscle groups [49]. During the whole exercise program (Phases A-D), $\mathrm{T}_{\mathrm{GM}}$ had a non-normal distribution (Table A1). It may due to the various depths of microchip location in the biggest muscle or different muscle compartments work individually [46,47].

Although the different muscle sites used in the present study actively engage differently during exercise, temperature change followed a very similar pattern, with all rising rapidly to exceed rectal temperature. Previous studies found that PTSMs were a reliable alternative to rectal thermometry for the measurement of body temperature in equids at rest in an ambient temperature $>15.6{ }^{\circ} \mathrm{C}$ [50]. In the current study, temperatures obtained using PTSMs had a poor correlation with rectal temperature during exercise. This is likely due to thermal inertia and a higher dependence on conductive heat transfer by blood. Rectal temperature responds more slowly in comparison to core body temperature and PTSM temperatures [51,52]. Ambient temperature may have affected PTSM values. The ambient temperature during exercise in our study was between $18.9^{\circ} \mathrm{C}$ and $21.7^{\circ} \mathrm{C}$. In a previous study, the effect of ambient temperature on PTSMs placed in the nuchal ligament was evaluated in horses at rest. In that study, the PTSMs underestimated rectal temperatures $<38.9^{\circ} \mathrm{C}$ and overestimated rectal temperatures $\geq 38.9^{\circ} \mathrm{C}$ at an ambient temperature of $21.2^{\circ} \mathrm{C}$ [35].

Obtaining rectal temperatures in racehorses immediately after a race is both time-consuming and risky for the operator. In the current study, it was found that the mean temperature differences between $T_{C V}$ and $T_{R}$ in the period between 3 and $5 \mathrm{~min}$ in Phase $\mathrm{D}$ were the least among the other temperature pairs during the same period, suggesting that the attainment of rectal temperature has value postrace. However, the lower correlation between the temperatures during Phase $\mathrm{D}$ and the risk factors to handlers may negate the value. $T_{R}$ showed a moderate correlation with $T_{C V}$ during the whole treadmill test, but it was weaker than the microchip temperatures. Based on the results from the current study, it is recommended that rectal temperature should not be used as a measurement postexercise, not only for safety reasons but also because of the poor correlation with the central venous temperature immediately after exercise and at least $8 \mathrm{~min}$ postexercise. Since it is believed that the first 8 to $10 \mathrm{~min}$ after the race is the most likely period to detect horses with emerging signs of EHI, it was found that only one study collected the temperature after the cool-down phase ( 8 to $10 \mathrm{~min}$ postexercise) of the experiment [53]. In the current study, $\mathrm{T}_{\mathrm{CV}}$ began to decrease as soon as exercise at maximum speed ceased in Phase $B$, and $T_{R}$ continuously increased until the end of Phase $D$. The continuous increase in $T_{R}$ has been observed in previous studies [23,54] during the first 10 min of walking recovery when horses were allowed to cool passively. This resulted from the heat redistribution produced by muscle activity to the skin and other compartments (gastrointestinal tract including the rectum) $[55,56]$.

Intramuscular implantation of the PTSM is minimally invasive, requiring only the injection of the microchip through a large gauge needle like the conventional ID microchip insertion [57]. After initial implantation, measuring body temperature is completely noninvasive. No adverse reactions were observed concerning the microchip implantation site, and the procedure was well tolerated by all horses. Microchip migration is often suggested as a problem [58]; however, the migration or movement 
of the microchips was not observed in the short follow-up period of this experiment, and the readability of the microchips was obtained six months after implantation (unpublished data). The horses showed no limitations to movement by having the microchips placed in their muscles. Other advantages of using PTSMs include the speed and ease of use, life-long battery life of the microchips, and the rechargeable microchip reader, and it is also possible to include the unique identification number assigned to each horse [35,37].

A strong positive correlation $(r=0.84, p<0.001)$ was found between gluteal percutaneous thermal sensing microchips, and central venous temperatures prompted the investigation for additional muscle sites to implant microchips. Even though the current study showed a high correlation between core body temperature and PTSM in the gluteal region, near the hind limbs, and pectoral, between the front legs, measurements were considered to be an unsafe location when handling potentially excitable horses postexercise or when showing EHI signs. Acquisition of the temperatures during exercise was possible due to the experiment design on the treadmill. However, obtaining PTSM temperatures during exercise in field conditions will have limited practical application.

The protocol within the current study was for individual horses to reach a central venous temperature of $41{ }^{\circ} \mathrm{C}$. As unconditioned horses were used in the study and each animal presented different performance abilities, the exercise protocol varied slightly between horses, and this may have influenced the results. However, the core body temperature increased by $1{ }^{\circ} \mathrm{C} / \mathrm{min}$ during exercise obtained in the current study is in agreement with what has been published for horses during high-speed exercise [8].

The goal of the current study was to analyze the relation of temperatures obtained from various sites with the central venous temperature. In this study, in all locations of PTSMs, strong positive correlations between the core temperature and microchip temperatures were noted prior to, during, and immediately after strenuous exercise on the treadmill, while rectal temperature had a moderate correlation with the core body temperature. Prior to the exercise, only the pectoral and splenius muscles had a statistically significant strong positive correlation with $\mathrm{T}_{\mathrm{CV}}$. However, during this phase, the temperature data were obtained only once, which generates a low sample size. It is required to collect more data in order to assess the correlation between the muscle and central venous temperatures at rest. This work has focused largely on the analysis of temperatures during and immediately after exercise. All the different locations of PTSMs had strong positive correlations with the core body temperature during and immediately after exercise on the treadmill, while rectal temperature had a moderate correlation with the core body temperature. As it was inferred previously, the strong correlations between PTSMs temperature and $\mathrm{T}_{\mathrm{CV}}$, as well as narrow LOA, PTSMs in the different muscle sites can estimate the core body temperature during and immediately after exercise on the treadmill. However, more work is needed to validate the data presented here under racetrack conditions. The use of PTSMs also would allow for further investigation in the most efficient cooling techniques and, ultimately, the best procedures to decrease EHI prevalence at the racetrack.

\section{Conclusions}

In summary, this study demonstrated the easy use of PTSMs for measuring the body temperature of horses during and immediately after exercise. The pectoral muscle was the most reliable implantation site for PTSM to track temperature changes among the three different muscles in this experimental study.

These results are promising in regards to finding a simple, safe, quick, accurate, and noninvasive method to measure the body temperature of horses immediately after high-speed exercise

Future studies are needed to validate this method under field conditions and in equine athletes working in extreme environments and intensive activity in various equestrian sports.

Author Contributions: Conceptualization, A.S.G. and J.B.G.; methodology, A.S.G.; software, J.B.G. and R.R.Z.; validation, A.S.G., J.B.G. and R.R.Z.; formal analysis, A.S.G., R.R.Z. and S.M.W.; investigation, A.S.G.; resources, A.S.G., J.B.G. and R.R.Z.; data curation, H.K., J.B.G., R.R.Z. and S.M.W.; writing-original draft preparation, H.K.; writing-review and editing, A.S.G., J.B.G. and R.R.Z.; visualization, A.S.G., R.R.Z. and S.M.W.; supervision, 
A.S.G. and R.R.Z.; project administration, A.S.G. All authors have read and agreed to the published version of the manuscript.

Funding: This work was supported by the Maria Vasas Foundation.

Acknowledgments: The authors wish to thank all the nursing team and students at UQ VETS-ESH for their support during the treadmill study and the Equine Unit at The University of Queensland, Gatton for the care of the horses.

Conflicts of Interest: The authors declare no conflict of interest.

\section{Appendix A}

\section{Appendix A.1 Repeated-Measures Correlation Coefficient (rrm)}

We used the rmcorr and plot.rmc functions from the rmcorr package, respectively, for computing the repeated-measures correlation coefficient $\left(\mathrm{r}_{\mathrm{rm}}\right)$ and producing a scatterplot of the repeated-measures paired data, with each participant's data plotted in a different color. The rmcorr is estimated using ANCOVA. The rmctorr effect size is estimated using confidence intervals obtained through bootstrapping, which does not require distributional assumptions and uses random resampling to estimate parameter accuracy [59].

Based on the sums of squares values for the measure and error, the repeated-measures correlation coefficient $\left(\mathrm{r}_{\mathrm{rm}}\right)$ is calculated as follows:

$$
\mathrm{r}_{\mathrm{rm}}=\sqrt{\frac{\text { SSMeasure }}{\text { SSMeasure }+ \text { SSError }}}
$$

We followed the guide for interpreting the size of a correlation coefficient used by Mukaka [60] and Akoglu [39].

\section{Appendix A.2 Linear Mixed-Effects Model}

In order to compute the limit of agreement (LOA) between the body temperature readings obtained by the various methods with that of the $\mathrm{T}_{\mathrm{CV}}$, linear mixed-effects models were fitted to the observed differences of body temperature readings.

The basic linear mixed-effects model (LMM) is of the form:

$$
\mathrm{y}_{\mathrm{ijkt}}=\mu+\alpha_{\mathrm{i}}+\beta_{\mathrm{j}}+\gamma_{\mathrm{k}}+\varepsilon_{\mathrm{ijkt}}
$$

where $y_{\mathrm{ijlt}}$ represents the body temperature reading/measurement made on HORSE $i$ by device $j$ with VEL $k$ at time $t, \mu$ is the overall mean; $\alpha_{\mathrm{i}} \sim \mathrm{N}\left(0, \sigma^{2}\right)$ is the random HORSE effect, $\beta_{\mathrm{j}}$ is the fixed effect of device $\mathrm{j}, \gamma_{\mathrm{k}} \sim \mathrm{N}\left(0, \sigma^{2}{ }_{\mathrm{k}}\right), \gamma_{\mathrm{k}}$ denotes the random VEL effect, and $\varepsilon_{\mathrm{ijlt}} \sim \mathrm{N}\left(0, \sigma_{\varepsilon}{ }_{\varepsilon}\right)$ is the residual error.

The LMM in Equation (A2) can be modified to fit the corresponding model for fitting the differences as follows:

$$
y_{\text {ilkt }}=\mu+\alpha_{i}+\beta_{j}+\gamma_{k}+\varepsilon_{i j k t}
$$

where $y_{i k t}$ represents the differences in body temperature readings made on HORSE $i$ with VEL $k$ at time $t, \mu$ is the overall mean, $\alpha_{\mathrm{i}} \sim \mathrm{N}\left(0, \sigma^{2}\right)$ is the random HORSE effect, $\beta_{\mathrm{j}}$ is the fixed effects, $\gamma_{\mathrm{k}} \sim \mathrm{N}(0$, $\left.\sigma^{2}{ }_{k}\right), \gamma_{k}$ denotes the random VEL effect, and $\varepsilon_{i j l t} \sim N\left(0, \sigma^{2}{ }_{\varepsilon}\right)$ is the residual error.

The model specified in (3) is used to get the total variance required to compute the corresponding LOA and the additional null model with only a random-effects mean bias.

The initial full model was fitted with Age, Weight, Breed, and Heart Rate (HR) as fixed effects with random effects for HORSE, TIME, and VEL on the observed differences (the difference of the horse body temperature readings between body temperature obtained by any of the four methods and body temperature obtained by $\mathrm{T}_{\mathrm{CV}}$ ). The final full model was then run with statistically significant fixed effects and the random effects to get the between variances of the random effects and residual 
error variances. Accordingly, the standard error (SE) for obtaining the confidence intervals [61] for the LOA was computed using the following formula:

$$
S E=\sqrt{\text { Var }_{\text {Horse }}+\text { Var }_{\text {Time }}+\text { Var }_{\text {Vel }}+\text { Var }_{\text {Residual }}}
$$

where

$$
\begin{aligned}
\operatorname{Var}_{\text {Horse }}= & \text { variance due to horse to horse variability; } \\
& \operatorname{Var}_{\text {Time }}=\text { variance across time; } \\
& \operatorname{Var}_{\text {Vel }}=\text { variance across velocity. }
\end{aligned}
$$

Finally, the null model consisting of only the random effects of HORSE, TIME, and VEL was fitted to get the mean bias in the observed body temperature differences. Accordingly, the $95 \% \mathrm{CI}$ for the limit of agreement was computed using the following formula:

$$
\mu_{\mathrm{b}} \pm \mathrm{Z}_{\alpha / 2} * \mathrm{SE}
$$

\begin{tabular}{|c|c|c|}
\hline & \multicolumn{2}{|c|}{ Normality Test } \\
\hline & Statistic & $p$-Value \\
\hline \multicolumn{3}{|c|}{ Phase A (Prior to exercise) } \\
\hline $\mathrm{T}_{\mathrm{CV}}$ & 0.969 & 0.893 \\
\hline $\mathrm{T}_{\mathrm{PM}}$ & 0.904 & 0.316 \\
\hline $\mathrm{T}_{\mathrm{GM}}$ & 0.984 & 0.981 \\
\hline $\mathrm{T}_{\mathrm{SM}}$ & 0.929 & 0.506 \\
\hline $\mathrm{T}_{\mathrm{R}}$ & 0.765 & $0.012 *$ \\
\hline \multicolumn{3}{|c|}{ Phase B (Exercise on the treadmill) } \\
\hline $\mathrm{T}_{\mathrm{CV}}$ & 0.918 & 0.413 \\
\hline $\mathrm{T}_{\mathrm{PM}}$ & 0.841 & 0.167 \\
\hline $\mathrm{T}_{\mathrm{GM}}$ & 0.945 & 0.657 \\
\hline $\mathrm{T}_{\mathrm{SM}}$ & 0.946 & 0.674 \\
\hline $\mathrm{T}_{\mathrm{R}}$ & 0.958 & 0.795 \\
\hline \multicolumn{3}{|c|}{ Phase C (Immediately after treadmill) } \\
\hline $\mathrm{T}_{\mathrm{CV}}$ & 0.93 & 0.512 \\
\hline $\mathrm{T}_{\mathrm{PM}}$ & 0.941 & 0.621 \\
\hline $\mathrm{T}_{\mathrm{GM}}$ & 0.942 & 0.633 \\
\hline $\mathrm{T}_{\mathrm{SM}}$ & 0.792 & 0.023 * \\
\hline $\mathrm{T}_{\mathrm{R}}$ & 0.983 & 0.975 \\
\hline \multicolumn{3}{|c|}{ Phase D (Cool-down walk) } \\
\hline $\mathrm{T}_{\mathrm{CV}}$ & 0.921 & 0.438 \\
\hline $\mathrm{T}_{\mathrm{PM}}$ & 0.914 & 0.385 \\
\hline $\mathrm{T}_{\mathrm{GM}}$ & 0.943 & 0.637 \\
\hline $\mathrm{T}_{\mathrm{SM}}$ & 0.941 & 0.618 \\
\hline $\mathrm{T}_{\mathrm{R}}$ & 0.899 & 0.281 \\
\hline \multicolumn{3}{|c|}{ All the data (Phases A-D) } \\
\hline $\mathrm{T}_{\mathrm{CV}}$ & 0.94 & 0.076 \\
\hline $\mathrm{T}_{\mathrm{PM}}$ & 0.931 & 0.057 \\
\hline $\mathrm{T}_{\mathrm{GM}}$ & 0.905 & $0.008 *$ \\
\hline $\mathrm{T}_{\mathrm{SM}}$ & 0.94 & 0.077 \\
\hline $\mathrm{T}_{\mathrm{R}}$ & 0.954 & 0.184 \\
\hline
\end{tabular}

where $\mu_{\mathrm{b}}$ is the the mean bias and $\alpha$ is the level of significance

Table A1. Normality tests of body temperature readings of horses before, during, and after treadmill exercise.

\footnotetext{
* refers to non-normal distributed data and hence the Spearman rank correlation coefficient, median, and interquartile range were reported. $\mathrm{T}_{\mathrm{CV}}=$ central venous temperature, $\mathrm{T}_{\mathrm{PM}}=$ pectoral muscle temperature, $\mathrm{T}_{\mathrm{GM}}=$ gluteal muscle temperature, $\mathrm{T}_{\mathrm{SM}}=$ splenius muscle temperature, $\mathrm{T}_{\mathrm{R}}=$ rectal temperature.
} 
Table A2. Limit of agreement (LOA) for body temperature readings of horses before, during, and after treadmill exercise.

\begin{tabular}{cccccc}
\hline & \multicolumn{2}{c}{ LOA } & \multicolumn{2}{c}{ Normality Test } \\
\hline \multicolumn{1}{c}{ Mean Bias } & LL & UL & Statistic & $p$-Value \\
\hline Phase A (Prior to exercise) & & & & \\
$\mathrm{T}_{\mathrm{PM}}$ & 0.40 & 0.261 & 0.539 & 0.89 & 0.22 \\
$\mathrm{~T}_{\mathrm{GM}}$ & 0.388 & 0.13 & 0.645 & 0.83 & 0.07 \\
$\mathrm{~T}_{\mathrm{SM}}$ & -0.088 & -0.274 & 0.099 & 0.96 & 0.85 \\
$\mathrm{~T}_{\mathrm{R}}$ & -0.195 & -0.438 & 0.048 & 0.87 & 0.14 \\
\hline Phase B (Exercise on the treadmill) & & & & \\
$\mathrm{T}_{\mathrm{PM}}$ & 0.199 & -0.058 & 0.297 & 0.95 & 0.72 \\
$\mathrm{~T}_{\mathrm{GM}}$ & 0.076 & -0.052 & 0.204 & 0.90 & 0.26 \\
$\mathrm{~T}_{\mathrm{SM}}$ & 0.254 & -0.09 & 0.599 & 0.92 & 0.46 \\
$\mathrm{~T}_{\mathrm{R}}$ & 0.647 & 0.488 & 0.813 & 0.97 & 0.86 \\
\hline Phase C (Immediately after treadmill) & & & & \\
$\mathrm{T}_{\mathrm{PM}}$ & -0.5 & -0.851 & -0.149 & 0.90 & 0.31 \\
$\mathrm{~T}_{\mathrm{GM}}$ & -0.575 & -0.787 & -0.363 & 0.94 & 0.60 \\
$\mathrm{~T}_{\mathrm{SM}}$ & -0.075 & -0.691 & 0.541 & 0.80 & 0.03 \\
$\mathrm{~T}_{\mathrm{R}}$ & 1.496 & 1.131 & 1.861 & 0.91 & 0.33 \\
\hline Phase $\mathrm{D}$ (Cool-down walk) & & & & \\
$\mathrm{T}_{\mathrm{PM}}$ & -0.768 & -1.23 & -0.307 & 0.98 & 0.96 \\
$\mathrm{~T}_{\mathrm{GM}}$ & -1.172 & -1.515 & -0.829 & 0.88 & 0.19 \\
$\mathrm{~T}_{\mathrm{SM}}$ & -1.018 & -1.537 & -0.499 & 0.97 & 0.85 \\
$\mathrm{~T}_{\mathrm{R}}$ & 0.034 & -0.217 & 0.286 & 0.91 & 0.32 \\
\hline
\end{tabular}

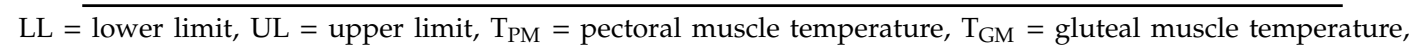
$\mathrm{T}_{\mathrm{SM}}=$ splenius muscle temperature, $\mathrm{T}_{\mathrm{R}}=$ rectal temperature.

Table A3. Limit of agreement (LOA) of body temperature readings of horses during Phases B (exercise on the treadmill) and D (cool-down walking).

\begin{tabular}{cccc}
\hline & Mean Bias & Lower Limit & Upper Limit \\
\hline $\mathrm{T}_{\mathrm{PM}}$ & -0.319 & -1.078 & 0.441 \\
$\mathrm{~T}_{\mathrm{GM}}$ & -0.459 & -1.078 & 0.441 \\
$\mathrm{~T}_{\mathrm{SM}}$ & -0.26 & -1.653 & 1.134 \\
$\mathrm{~T}_{\mathrm{R}}$ & 0.483 & -0.787 & 1.799 \\
\hline
\end{tabular}

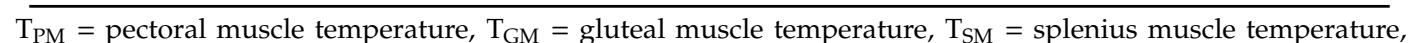
$\mathrm{T}_{\mathrm{R}}=$ rectal temperature.

\section{References}

1. Racing Australia. A Guide to the Racing Industry in Australia 2017-2018. Available online: http:// publishingservices.risa.com.au/otherpublications/Fact\%20Book\%202017-2018/ (accessed on 31 March 2020).

2. Racing Australia. A Guide to the Racing Industry in Australia 2018-2019. Available online: http:// publishingservices.risa.com.au/otherpublications/FactBook2018-2019/ (accessed on 31 March 2020).

3. Racing NSW. Racing in Hot Weather. Available online: http://www.racingnsw.com.au/site/_content/ document/00000048-source.pdf (accessed on 6 October 2020).

4. Racing Victoria. Hot Weather Racing Policy. Available online: http://www.rv.racing.com/notices/2014-07-07/ hot-weather-policy (accessed on 6 October 2020).

5. Racing Queensland. Animal Welfare Policy. Available online: http://www.racingqueensland.com.au/Animal_ welfare_policy_1.pdf.aspx (accessed on 6 October 2020).

6. Racing and Wagering Western Australia. Racing horses in Hot Weather. Available online: http://www.rwwa. com.au/home/thoroughbredpolicy29.pdf (accessed on 6 October 2020).

7. Thoroughbred Racing Northern Territory. Racing Horses in Hot Weather. Policy no.014. Available online: www.trnt.org.au/racing-info/policies (accessed on 6 October 2020). 
8. Hodgson, D.R. Chapter 8-Thermoregulation. In The Athletic Horse, 2nd ed.; Hodgson, D.R., McKeever, K.H., McGowan, C.M., Eds.; W.B. Saunders: Philadelphia, PA, USA, 2014; pp. 108-124. [CrossRef]

9. Marlin, D.J.; Scott, C.M.; Schroter, R.C.; Mills, P.C.; Harris, R.C.; Harris, P.A.; Orme, C.E.; Roberts, C.A.; Marr, C.M.; Dyson, S.J.; et al. Physiological responses in nonheat acclimated horses performing treadmill exercise in cool (20 degrees $\mathrm{C} / 40 \% \mathrm{RH}$ ), hot dry (30 degrees $\mathrm{C} / 40 \% \mathrm{RH}$ ) and hot humid (30 degrees $\mathrm{C} / 80 \% \mathrm{RH}$ ) conditions. Equine Vet. J. 1996, 28, 70-84. [CrossRef]

10. Jones, J.H.; Carlson, G.P. Estimation of metabolic energy cost and heat production during a 3-day-event. Equine Vet. J. 1995, 27, 23-30. [CrossRef]

11. Lindinger, M.I. Exercise in the heat: Thermoregulatory limitations to performance in humans and horses. Can. J. Appl. Physiol. 1999, 24, 152-163. [CrossRef]

12. Geor, R.J.; McCutcheon, L.J.; Ecker, G.L.; Lindinger, M.I. Heat storage in horses during submaximal exercise before and after humid heat acclimation. J. Appl. Physiol. 2000, 89, 2283-2293. [CrossRef]

13. McCutcheon, L.J.; Geor, R.J. Equine Sports Medicine and Surgery, 2nd ed.; Elsevier Ltd.: Amsterdam, The Netherlands, 2014; pp. 901-918. [CrossRef]

14. McDonald, R.E.; Fleming, R.I.; Beeley, J.G.; Bovell, D.L.; Lu, J.R.; Zhao, X.; Cooper, A.; Kennedy, M.W. Latherin: A surfactant protein of horse sweat and saliva (Latherin Protein of horses). PLoS ONE 2009, 4, e5726. [CrossRef]

15. Guthrie, A.J.; Lund, R.J. Thermoregulation: Base mechanisms and hyperthermia. Vet. Clin. N. Am. Equine Pract. 1998, 14, 45-59. [CrossRef]

16. Kennedy, M.W. Latherin and other biocompatible surfactant proteins. Biochem. Soc. Trans. 2011, $39,1017$. [CrossRef]

17. Divers, T.J. Chapter 33-Temperature-related problems: Hypothermia and hyperthermia. In Equine Emergencies, 4th ed.; Orsini, J.A., Divers, T.J., Eds.; W.B. Saunders: St. Louis, MO, USA, 2014; pp. 573-577. [CrossRef]

18. Hodgson, D.R.; Davis, R.E.; McConaghy, F.F. Thermoregulation in the horse in response to exercise. Br. Vet. J. 1994, 150, 219-235. [CrossRef]

19. CouroucÉ-Malblanc, A.; Hodgson, D.R. Chapter 29-Clinical exercise testing. In The Athletic Horse, 2nd ed.; Hodgson, D.R., McKeever, K.H., McGowan, C.M., Eds.; W.B. Saunders: Philadelphia, PA, USA, 2014; pp. 366-378. [CrossRef]

20. Morgan, K.; Funkquist, P.; Nyman, G. The effect of coat clipping on thermoregulation during intense exercise in trotters. Equine Vet. J. 2002, 34, 564-567. [CrossRef]

21. Morgan, K. Effects of short-term changes in ambient air temperature or altered insulation in horses. J. Therm. Biol. 1997, 22, 187-194. [CrossRef]

22. Green, A.R.; Gates, R.S.; Lawrence, L.M. Measurement of horse core body temperature. J. Therm. Biol. 2005, 30, 370-377. [CrossRef]

23. Brownlow, M.; Dart, A.; Jeffcott, L. Exertional heat illness: A review of the syndrome affecting racing Thoroughbreds in hot and humid climates. Aust. Vet. J. 2016, 94, 240-247. [CrossRef]

24. Brownlow, M. Exertional heat illness in thoroughbred racehorses: Observations and treatment in the field. Proc. Int. Conf. Racing Anal. Vet. 2014, 20, 13-22.

25. Gagnon, D.; Lemire, B.B.; Casa, D.J.; Kenny, G.P. Cold-water immersion and the treatment of hyperthermia: Using $38.6{ }^{\circ} \mathrm{C}$ as a safe rectal temperature cooling limit. J. Athl. Train. 2010, 45, 439-444. [CrossRef]

26. Casa, J.D.; McDermott, P.B.; Lee, C.E.; Yeargin, W.S.; Armstrong, E.L.; Maresh, M.C. Cold water immersion: The gold standard for exertional heatstroke treatment. Exerc. Sport Sci. Rev. 2007, 35, 141-149. [CrossRef]

27. Gaudio, F.G.; Grissom, C.K. Cooling methods in heat stroke. J. Emerg. Med. 2016, 50, 607-616. [CrossRef]

28. Barwood, M.; Davey, S.; House, J.; Tipton, M. Post-exercise cooling techniques in hot, humid conditions. Eur. J. Appl. Physiol. 2009, 107, 385-396. [CrossRef]

29. Bongers, C.C.W.G.; Hopman, M.T.E.; Eijsvogels, T.M.H. Cooling interventions for athletes: An overview of effectiveness, physiological mechanisms, and practical considerations. Temperature 2017, 4, 60-78. [CrossRef]

30. Rizzo, M.; Arfuso, F.; Giudice, E.; Abbate, F.; Longo, F.; Piccione, G. Core and surface temperature modification during road transport and physical exercise in horse after acupuncture needle stimulation. J. Equine Vet. Sci. 2017, 55, 84-89. [CrossRef]

31. Verdegaal, E.; Jonas, S.; Caraguel, C.; Franklin, S. Real-time monitoring of the core body temperature of endurance horses during field exercise. Equine Vet. J. 2014, 46, 19-20. [CrossRef] 
32. Teunissen, L.P.J.; Daanen, H.A.M. Infrared thermal imaging of the inner canthus of the eye as an estimator of body core temperature. J. Med. Eng. Technol. 2011, 35, 134-138. [CrossRef]

33. Rey, B.; Fuller, A.; Hetem, R.S.; Lease, H.M.; Mitchell, D.; Meyer, L.C.R. Microchip transponder thermometry for monitoring core body temperature of antelope during capture. J. Therm. Biol. 2016, 55, 47-53. [CrossRef] [PubMed]

34. Yousuke, M.; Masa-Aki, O. Patterns of rectal temperature and shipping fever incidence in horses transported over long-distances. Front. Vet. Sci. 2019, 6. [CrossRef]

35. Robinson, T.R.; Hussey, S.B.; Hill, A.E.; Heckendorf, C.C.; Stricklin, J.B.; Traub-Dargatz, J.L. Comparison of temperature readings from a percutaneous thermal sensing microchip with temperature readings from a digital rectal thermometer in equids. J. Am. Vet. Med. Assoc. 2008, 233, 613-617. [CrossRef]

36. Rekant, S.I.; Lyons, M.A.; Pacheco, J.M.; Arzt, J.; Rodriguez, L.L. Veterinary applications of infrared thermography. Am. J. Vet. Res. 2016, 77, 98-107. [CrossRef]

37. Goodwin, S. Comparison of body temperatures of goats, horses, and sheep measured with a tympanic infrared thermometer, an implantable microchip transponder, and a rectal thermometer. Contem. Top. Lab. Anim. Sci. 1998, 37, 51-55.

38. R Core Team. R: A Language and Environment for Statistical Computing; R Foundation for Statistical Computing: Vienna, Austria, 2019.

39. Akoglu, H. User's guide to correlation coefficients. Turk. J. Emerg. Med. 2018, 18, 91-93. [CrossRef]

40. Garrett, P.D. Anatomy of the dorsoscapular ligament of horses. J. Am. Vet. Med. Assoc. 1990, 196, 446-448.

41. Guard, W.F. Fistula of the withers. N. Am. Vet. 1932, 13, 19-23.

42. Marlin, D.J.; Scott, C.M.; Roberts, C.A.; Casas, I.; Holah, G.; Schroter, R.C. Post exercise changes in compartimentai body temperature accompanying intermittent cold water cooling in the hyperthermic horse. Equine Vet. J. 1998, 30, 28-34. [CrossRef]

43. Lamb, D.R.; Gisolfi, C.V.; Nadel, E.R. Exercise, Heat, and Thermoregulation; Brown \& Benchmark: Cinccinati, OH, USA, 1993.

44. Ferguson, R.A.; Ball, D.; Sargeant, A.J. Effect of muscle temperature on rate of oxygen uptake during exercise in humans at different contraction frequencies. J. Exp. Biol. 2002, 205, 981-987.

45. Karvonen Äikäs, E.; Piironen, P.; Ruosteenoja, R. Intramuscular, rectal and oesophageal temperature during exercise. Acta Physiol. Scand. 1962, 54, 366-370. [CrossRef]

46. Glen, P.K.; Ollie, J. Sex differences in postexercise esophageal and muscle tissue temperature response. Am. J. Physiol. Regul. Integr. Comp. Physiol. 2007, 292, 1632-1640. [CrossRef]

47. Faulkner, S.H.; Ferguson, R.A.; Gerrett, N.; Hupperets, M.; Hodder, S.G.; Havenith, G. Reducing muscle temperature drop after warm-up improves sprint cycling performance. Med. Sci. Sports Exerc. 2013, 45, 359-365. [CrossRef] [PubMed]

48. Giesbrecht, G.G.; Bristow, G.K. A second postcooling afterdrop: More evidence for a convective mechanism. J. Appl. Physiol. 1992, 73, 1253-1258. [CrossRef]

49. Timothy, I.M.; Kevin, E.E.; Hageman, K.S.; David, C.P. Altered regional blood flow responses to submaximal exercise in older rats. J. Appl. Physiol. 2004, 96, 81-88. [CrossRef]

50. Auclair-Ronzaud, J.; Benoist, S.; Dubois, C.; Frejaville, M.; Jousset, T.; Jaffrézic, F.; Wimel, L.; Chavatte-Palmer, P. No-contact microchip monitoring of body temperature in yearling horses. J. Equine Vet. Sci. 2020, 86. [CrossRef]

51. Kenny, G.P.; Reardon, F.D.; Zaleski, W.; Reardon, M.L.; Haman, F.; Ducharme, M.B. Muscle temperature transients before, during, and after exercise measured using an intramuscular multisensor probe. J. Appl. Physiol. 2003, 94, 2350-2357. [CrossRef]

52. Ducharme, M.B.; Tikuisis, P. Role of blood as heat source or sink in human limbs during local cooling and heating. J. Appl. Physiol. 1994, 76, 2084-2094. [CrossRef]

53. Takahashi, Y.; Ohmura, H.; Mukai, K.; Shiose, T.; Takahashi, T. A comparison of five cooling methods in hot and humid environments in thoroughbred horses. J. Equine Vet. Sci. 2020, 91, 103130. [CrossRef]

54. Geor, R.J.; McCutcheon, L.J.; Ecker, G.L.; Lindinger, M.I. Thermal and cardiorespiratory responses of horses to submaximal exercise under hot and humid conditions. Equine Vet. J. 1995, 27, 125-132. [CrossRef]

55. Hales, J.R.S.; Bell, A.W.; Fawcett, A.A.; King, R.B. Redistribution of cardiac output and skin Ava activity in sheep during exercise and heat stress. J. Therm. Biol. 1984, 9, 113-116. [CrossRef] 
56. Johnson, J.M. Exercise in a hot environment: The skin circulation. Scand. J. Med. Sci. Sports. 2010, 20, $29-39$. [CrossRef]

57. Gerber, M.I.; Swinker, A.M.; Staniar, W.B.; Werner, J.R.; Jedrzejewski, E.A.; Macrina, A.L. Health factors associated with microchip insertion in horses. J. Equine Vet. Sci. 2012, 32, 177-182. [CrossRef]

58. Stein, F.J.; Geller, S.C.; Carter, J.C. Evaluation of microchip migration in horses, donkeys, and mules. J. Am. Vet. Med. Assoc. 2003, 223, 1316-1319. [CrossRef]

59. Bakdash, J.Z.; Marusich, L.R. Repeated measures correlation. Front. Psychol. 2017, 8. [CrossRef]

60. Mukaka, M.M. Statistics Corner: A guide to appropriate use of Correlation coefficient in medical research. Malawi Med. J. 2015, 24, 69-71.

61. Stewart, A.J.; Welles, E.G.; Salazar, T. Fungal infections of the upper respiratory tract. Compend. Equine 2008, 3, 208-220.

Publisher's Note: MDPI stays neutral with regard to jurisdictional claims in published maps and institutional affiliations.

(C) 2020 by the authors. Licensee MDPI, Basel, Switzerland. This article is an open access article distributed under the terms and conditions of the Creative Commons Attribution (CC BY) license (http://creativecommons.org/licenses/by/4.0/). 